\title{
elsevier_IE_2448
}

\section{Experimental study of laminated glass window responses under impulsive and blast loading}

Xihong Zhanga, *

xihong.zhang@uwa.edu.au

Hong $\mathrm{HaO}^{\mathrm{b}}$

Zhongqi Wang

aSchool of Civil, Environmental and Mining Engineering, The University of Western Australia, 35 Stirling Highway, Crawley, WA 6009, Australia

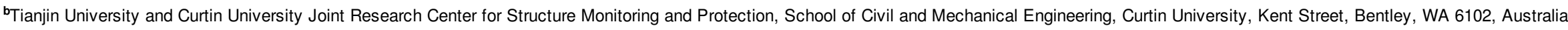

'The State Key Laboratory of Explosion Science and Technology, Beijing Institute of Technology, China

${ }^{*}$ Corresponding author.

\section{Abstract}

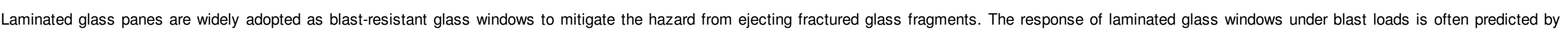

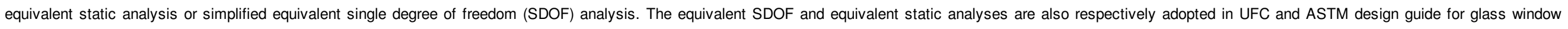

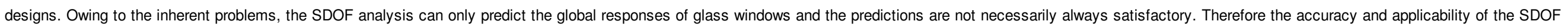

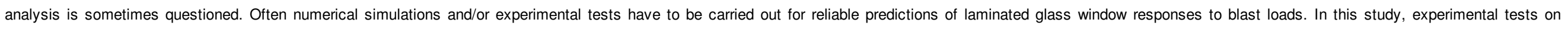

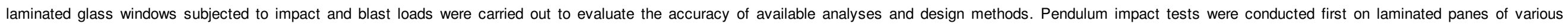

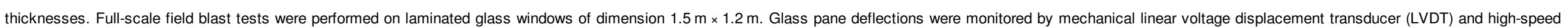

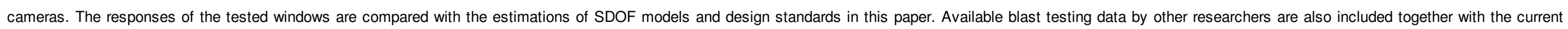

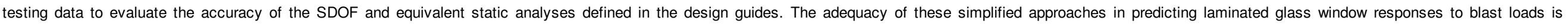
discussed.

Keywords: Laminated glass; Field blast test; Pendulum impact; SDOF

\section{Introduction}

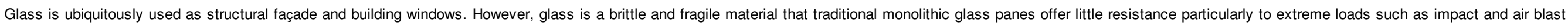

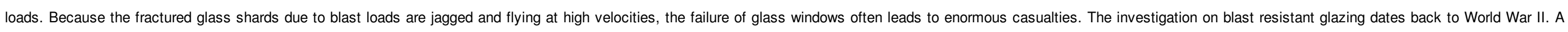

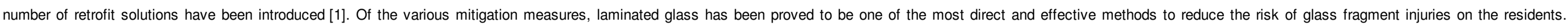

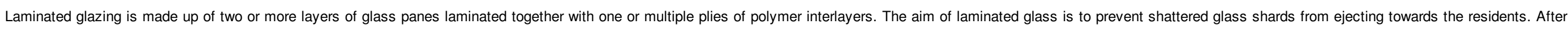

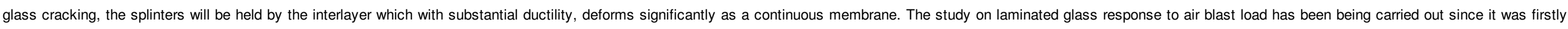

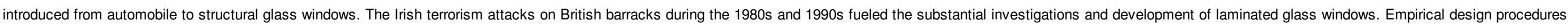

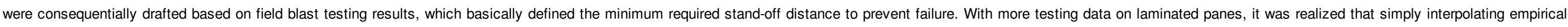

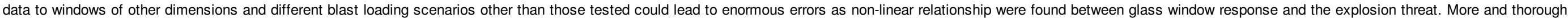
studies are therefore deemed necessary to better understand the response of laminated glass and to give more accurate estimation of laminated glass blast loading resistant capacities. 


\section{elsevier_IE_2448}

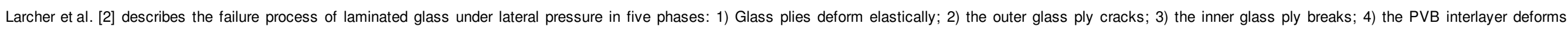

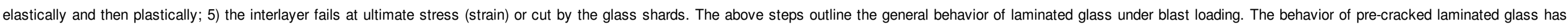

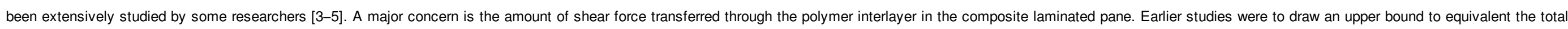

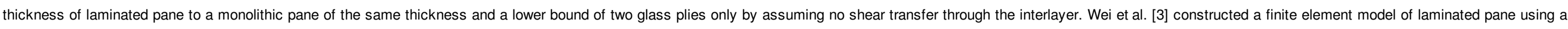

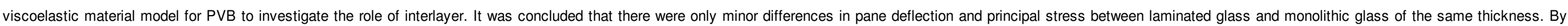

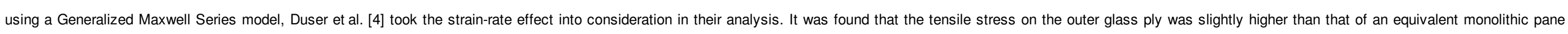

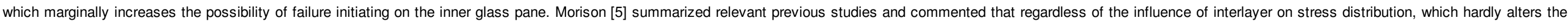

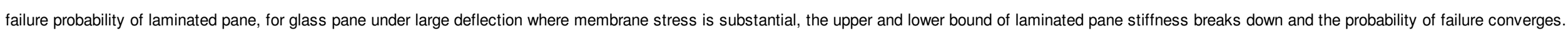

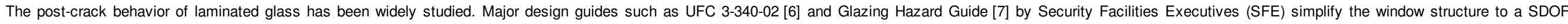

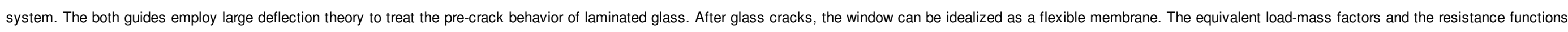

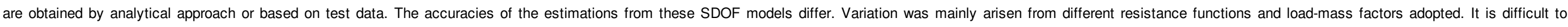

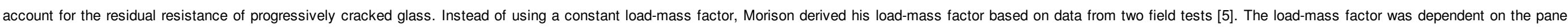

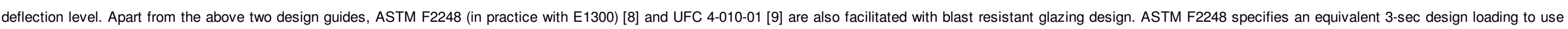

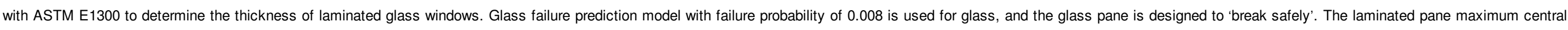

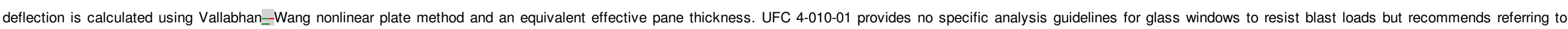

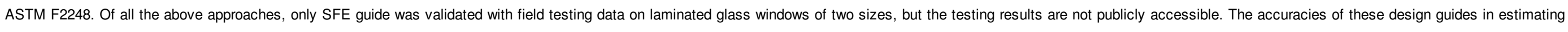
the response of laminated glass windows of different dimensions, materials and different blast loading scenarios need to be further checked.

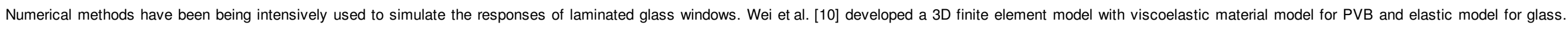

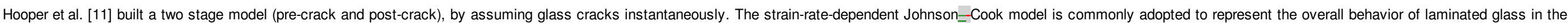

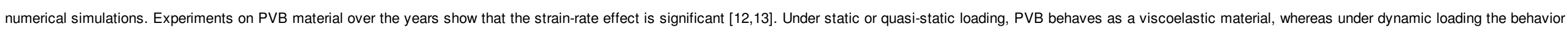

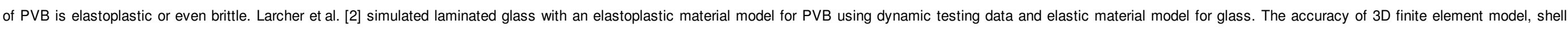

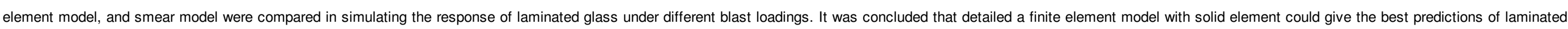

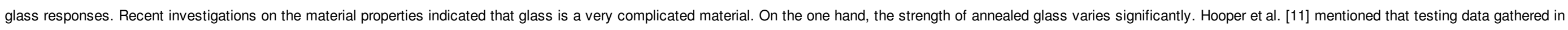

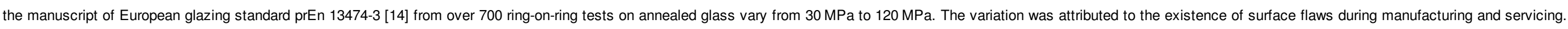

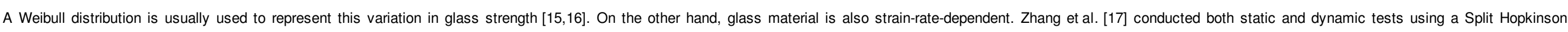

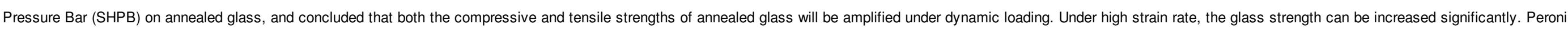

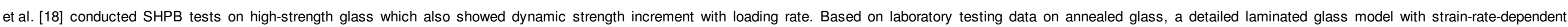

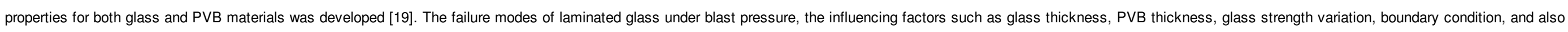
the vulnerability of laminated glass to debris impact were systematically studied [20,21].

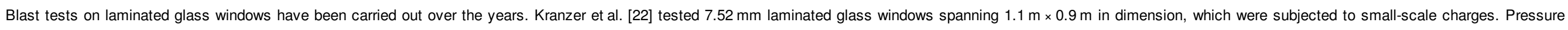

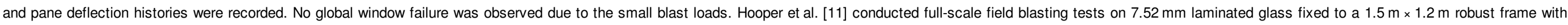

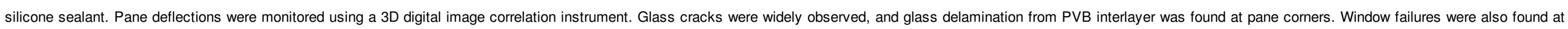

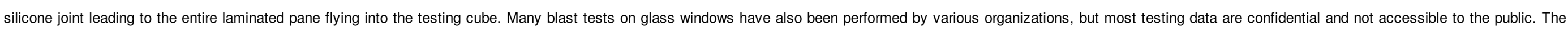

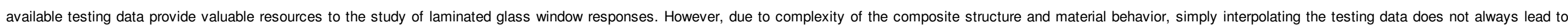

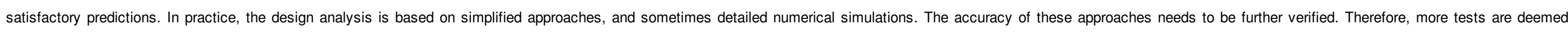

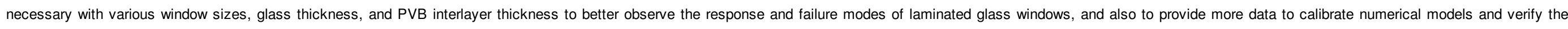
accuracy of the simplified design approaches in predicting the glass window responses to blast loads. 


\section{elsevier_IE_2448}

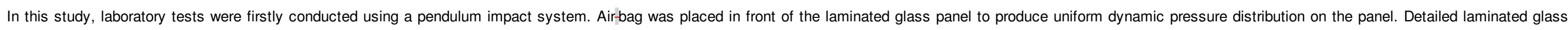

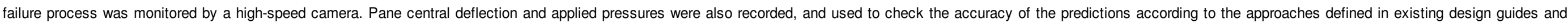

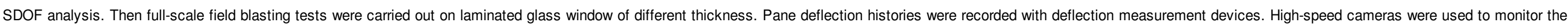

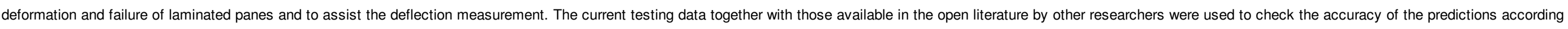
to the design guides, SDOF analysis, and numerical simulations.

\section{Laboratory test}

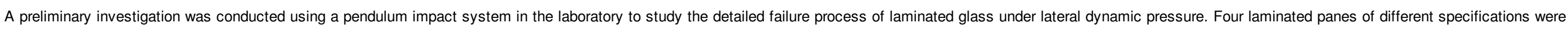
tested. The laminated specimens, the pendulum testing system and the experiment procedures are detailed in the following.

\subsection{Description of window specimen and testing system setup}

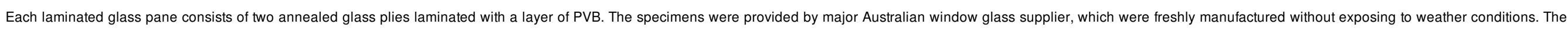

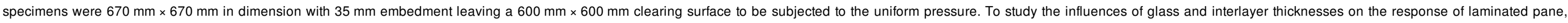
specimens with glass plies of $3 \mathrm{~mm}, 6 \mathrm{~mm}$ and PVB interlayer of $0.38 \mathrm{~mm}$ and $0.76 \mathrm{~mm}$ were considered. Table 1 lists the specifications of the tested panes.

\section{Table 1 Summary of laboratory impact test results.}

\begin{tabular}{|c|c|c|c|c|c|c|c|}
\hline Pane no. & $\begin{array}{l}\text { Glass } \\
(\mathrm{mm})\end{array}$ & $\begin{array}{l}\text { PVB } \\
(\mathrm{mm})\end{array}$ & $\begin{array}{l}\text { Total thickness } \\
(\mathrm{mm})\end{array}$ & $\begin{array}{l}\text { Dimension } \\
(\mathrm{mm} \times \mathrm{mm})\end{array}$ & $\begin{array}{l}\mathrm{Pr} \\
(\mathrm{kPa})\end{array}$ & $\begin{array}{c}\operatorname{Ir} \\
(\mathrm{kPa}-\mathrm{ms})\end{array}$ & $\begin{array}{l}w_{\max } \\
(\mathrm{mm})\end{array}$ \\
\hline 1 & 3 & 0.38 & 6.38 & $600 \times 600$ & 20.6 & 1684.0 & 29.4 \\
\hline 2 & 3 & 0.76 & 6.76 & $600 \times 600$ & 21.9 & 1825.9 & 31.9 \\
\hline 3 & 6 & 0.38 & 12.38 & $600 \times 600$ & 30.6 & 1984.6 & 7.4 \\
\hline 4 & 6 & 0.76 & 12.76 & $600 \times 600$ & 23.7 & 1466.0 & 6.5 \\
\hline
\end{tabular}

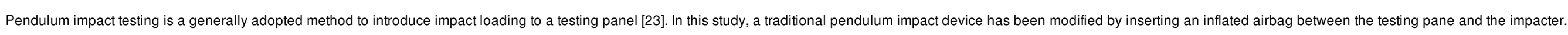

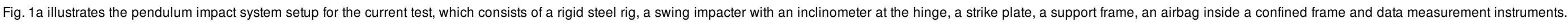

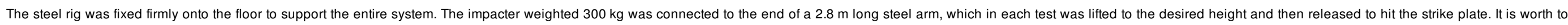

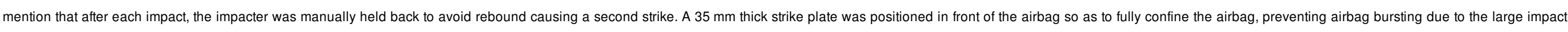

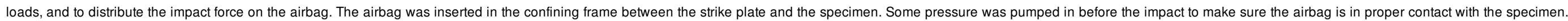

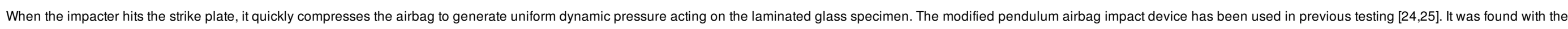
above setup a peak dynamic pressure of 20 to $30 \mathrm{kPa}$ (duration about $100 \mathrm{~ms}$ ) can be achieved when the impacter is lifted to $30^{\circ}$. 


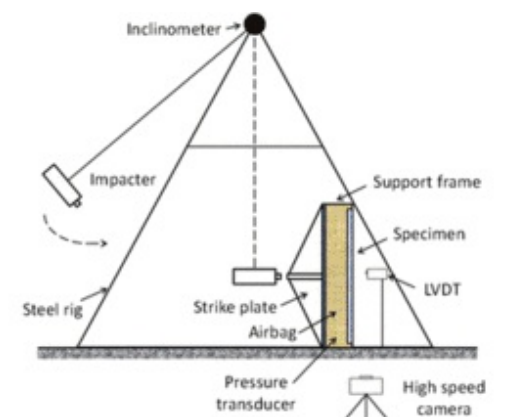

Pressure
transducer

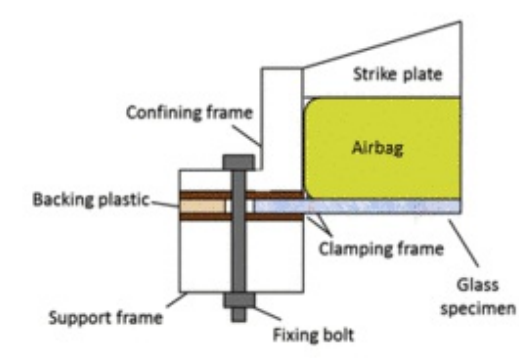

b) Schematic glass fixture

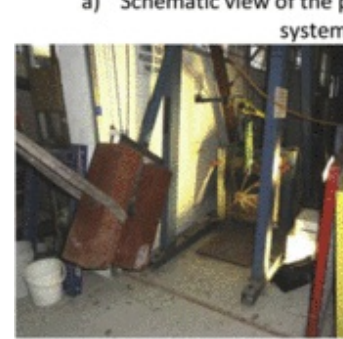

c) Ready-to-go pendulum

impact test

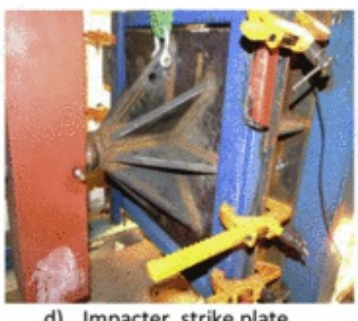

d) Impacter, strike plate, confining frame,
support frame

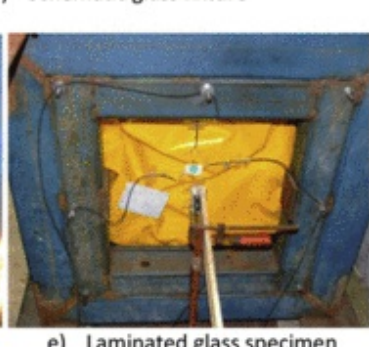

e) Laminated glass specimen

Fig. 1 Pendulum test setup.

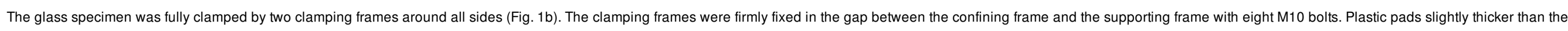
glass specimens were placed in the gap between the two clamping frames to ensure glass would not be damaged during installation by the clamping forces.

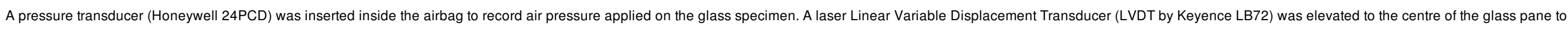

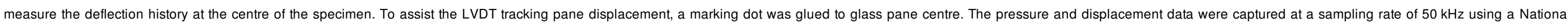

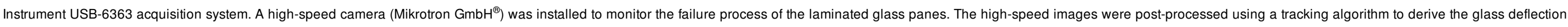

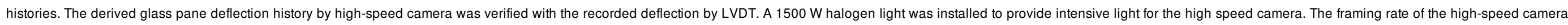
was set to $1500 \mathrm{fps}$. A group of strain gauges were glued on the outer glass ply intended to measure the strain of glass ply. However, due to the irregular cracking pattern of glass, no useful data were retrieved.

\subsection{Experiment results}

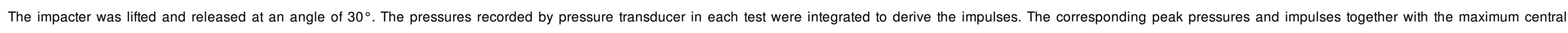

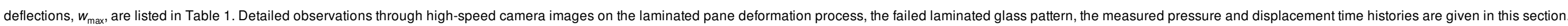

\subsubsection{Deformation process and failure pattern}

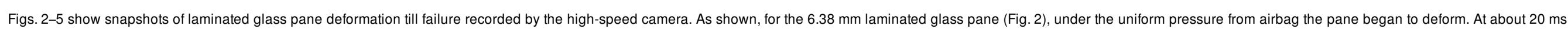

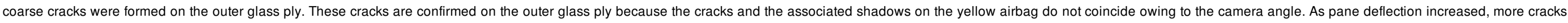

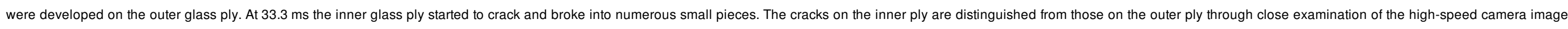

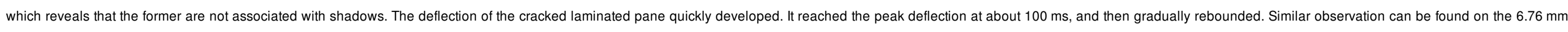

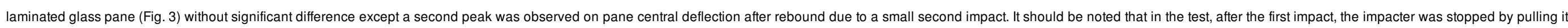

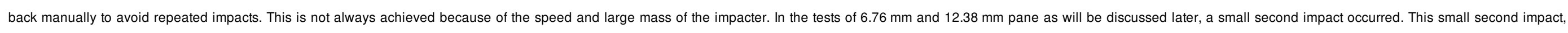




\section{elsevier_IE_2448}

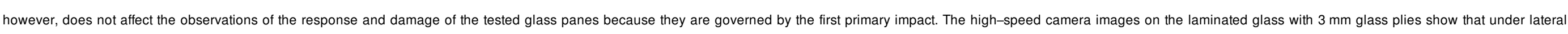

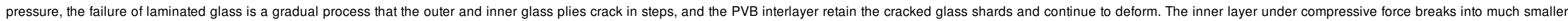
shards than the outer layer. As the pane deformation develops the cracked outer glass ply will further break into smaller shards. 

elsevier_IE_2448

Fig. 2 High-speed camera snapshots of $6.38 \mathrm{~mm}$ laminated pane.

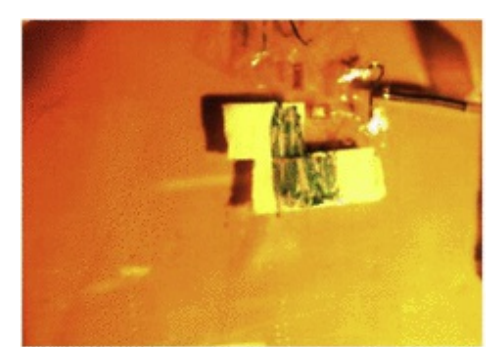

Oms impacter striked on airbag

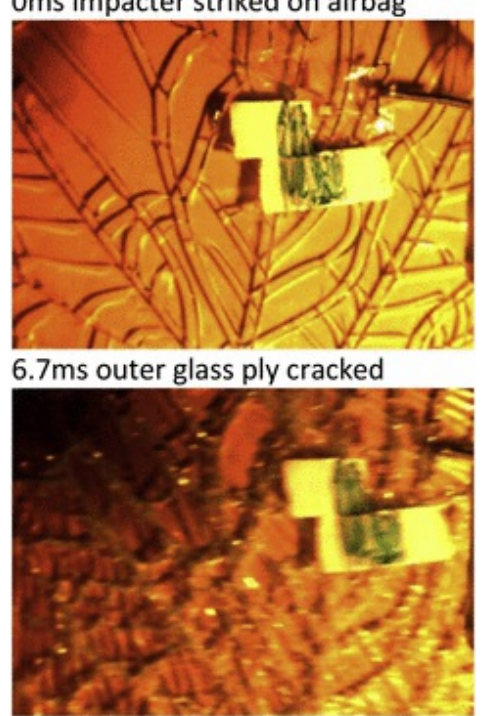

$20 \mathrm{~ms}$ innter glass ply cracked

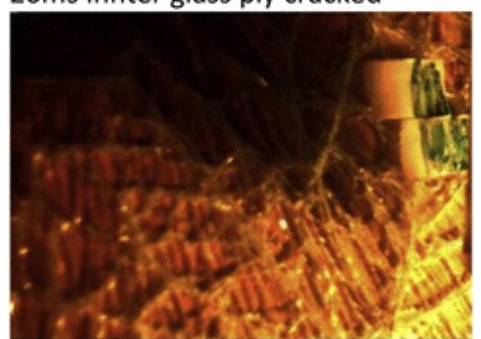

73.3ms maximum deflection

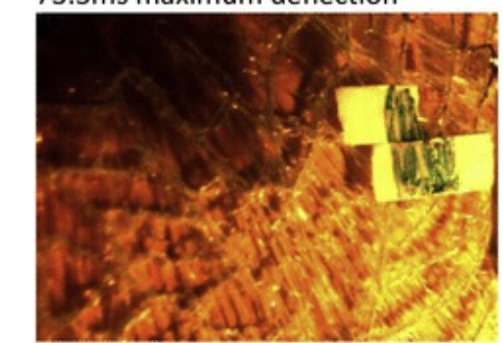




\section{elsevier_IE_2448}

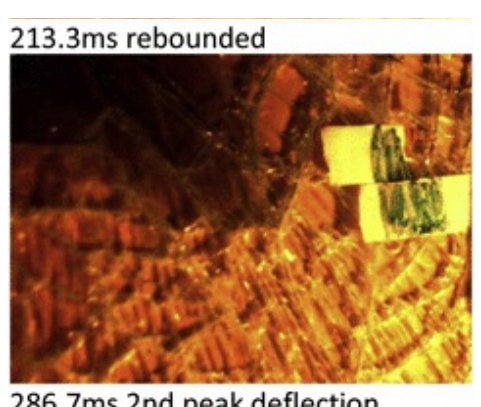

$286.7 \mathrm{~ms}$ 2nd peak deflection

Fig. 3 High-speed camera snapshots of $6.76 \mathrm{~mm}$ laminated pane.

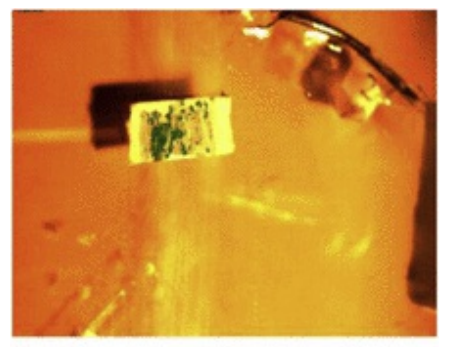

Oms impacter striked on airbag

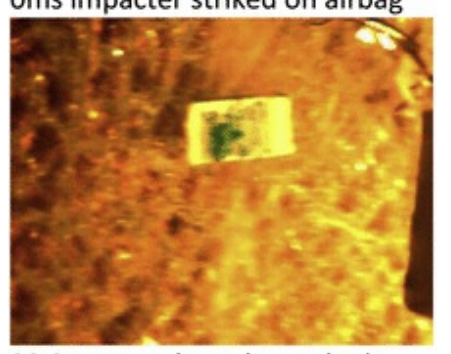

$33.3 \mathrm{~ms}$ out glass ply cracked

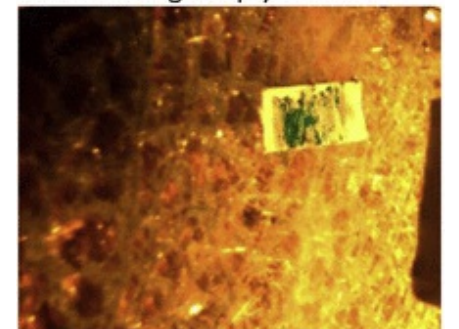

$40 \mathrm{~ms}$ inner glass ply cracked

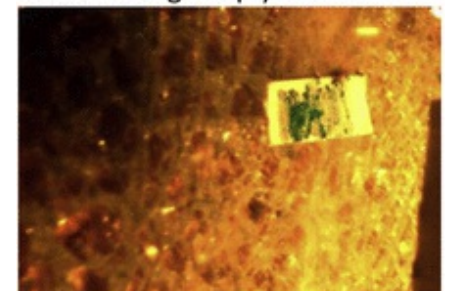


elsevier_IE_2448

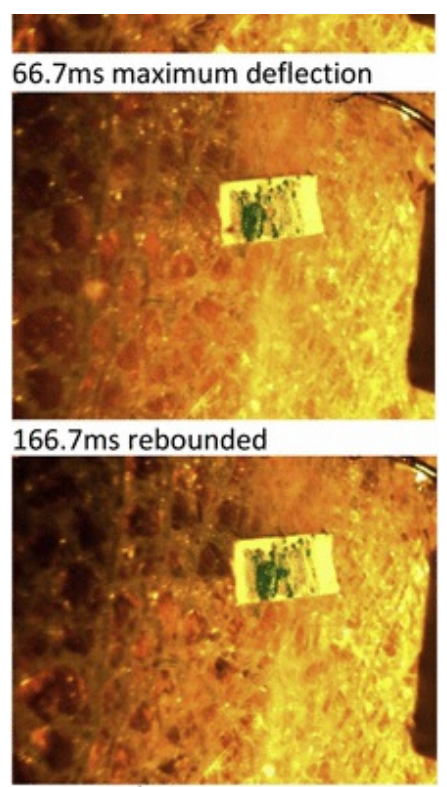

$200 \mathrm{~ms} 2^{\text {nd }}$ peak deflection

Fig. 4 High-speed camera snapshots of $12.38 \mathrm{~mm}$ laminated pane.

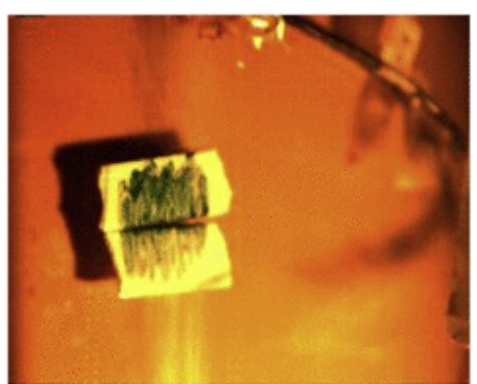

Oms impacter striked on airbag

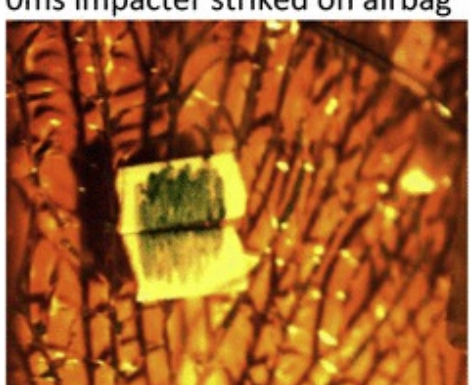

$33.3 \mathrm{~ms}$ outer glass ply cracked

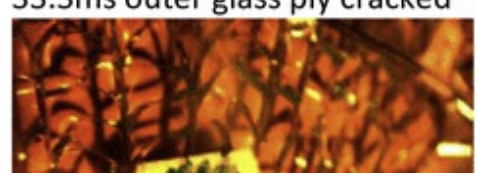




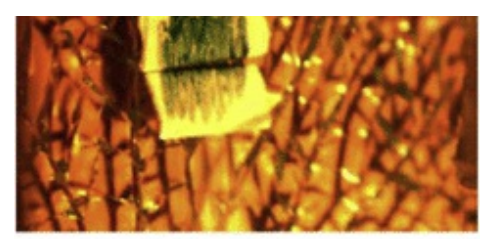

$40.7 \mathrm{~ms}$ inner glass ply cracked

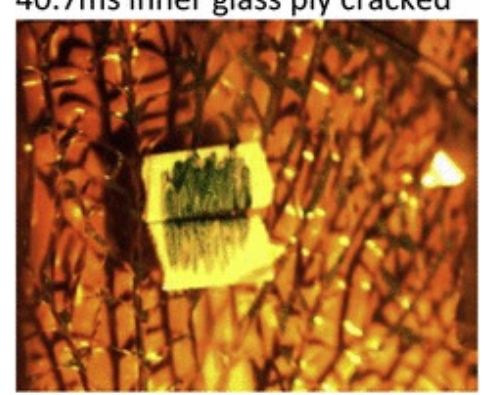

$86.7 \mathrm{~ms}$ maximum deflection

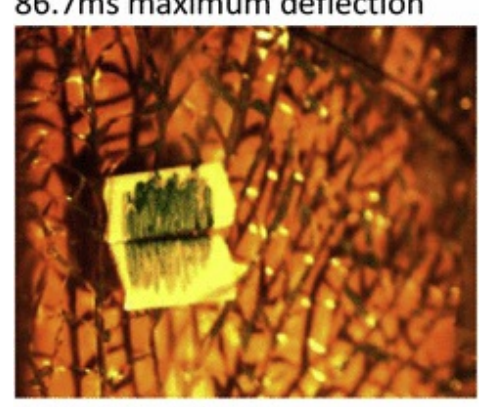

$150 \mathrm{~ms}$ rebounded

Fig. 5 High-speed camera snapshots of $12.76 \mathrm{~mm}$ laminated pane.

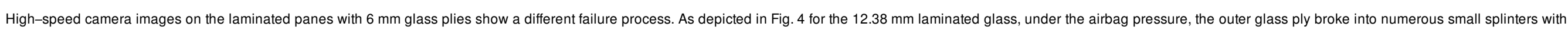

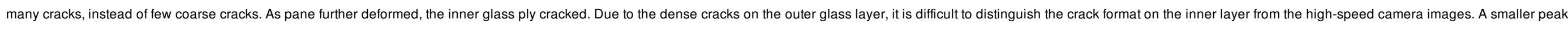

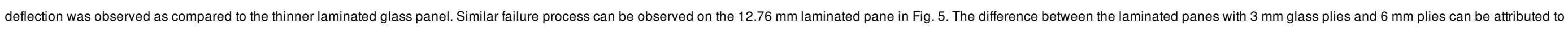
the stiffness difference of the two glass panes.

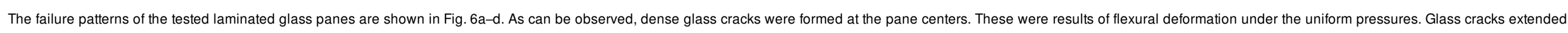

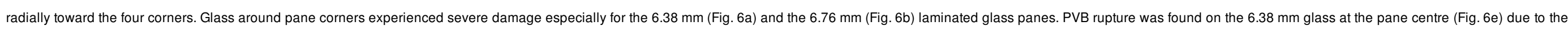

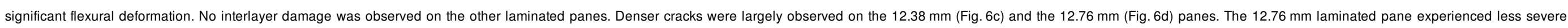
damage possibly due to the smaller pressure achieved in the impact test as indicated in Table 1. 


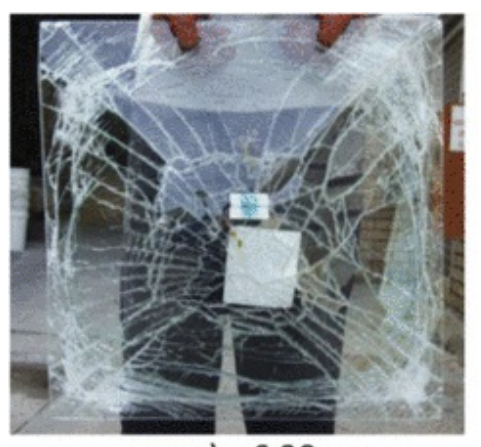

a) $6.38 \mathrm{~mm}$

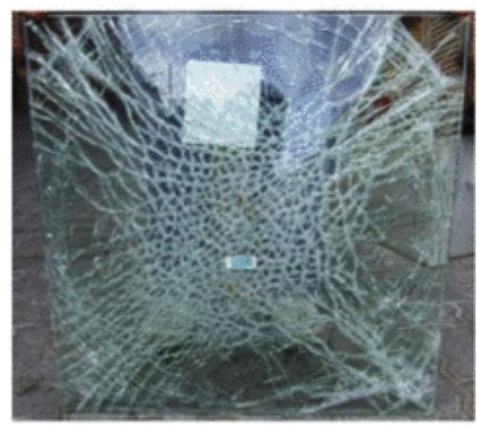

c) $12.38 \mathrm{~mm}$

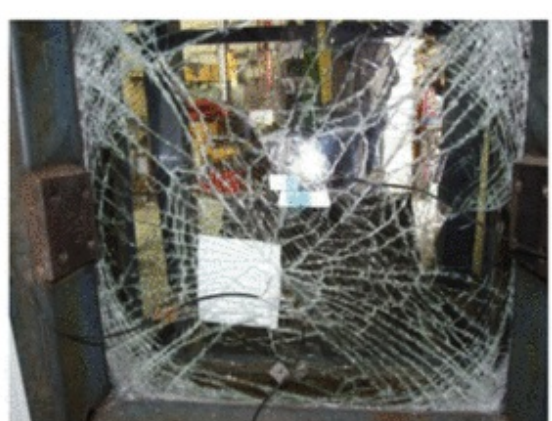

b) $6.76 \mathrm{~mm}$

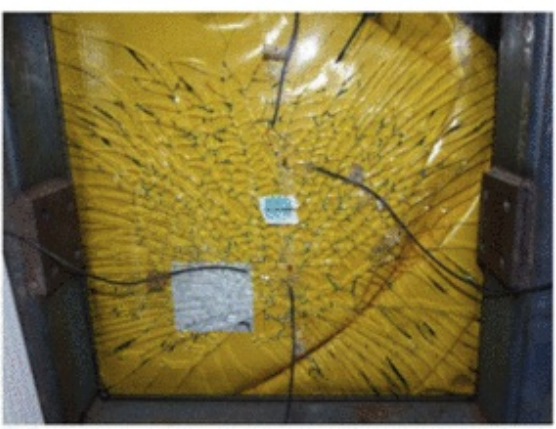

d) $12.76 \mathrm{~mm}$

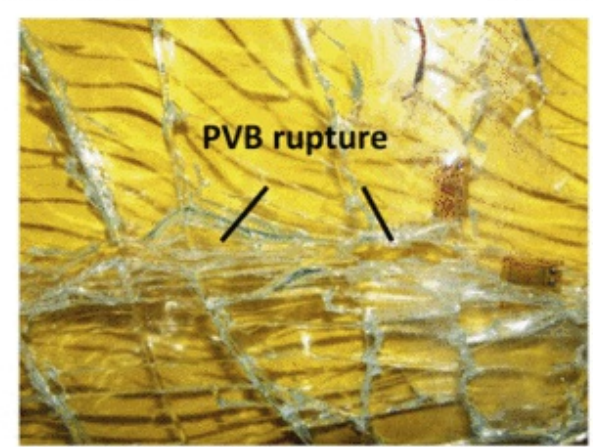

e) PVB rupture on $6.38 \mathrm{~mm}$ pane

Fig. 6 Failure patterns and details.

\subsubsection{Quantitative results}

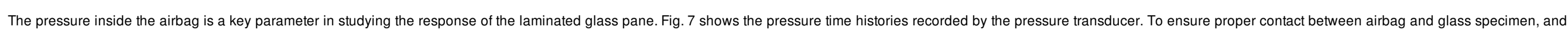

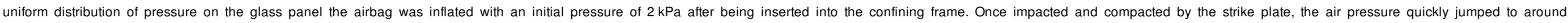

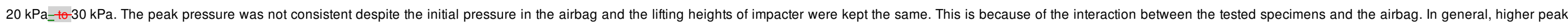

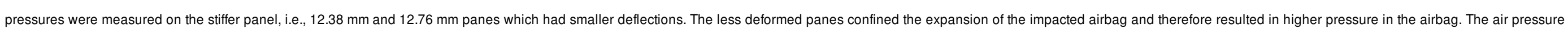

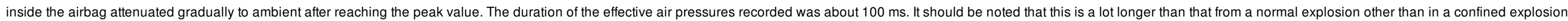
scenario. 


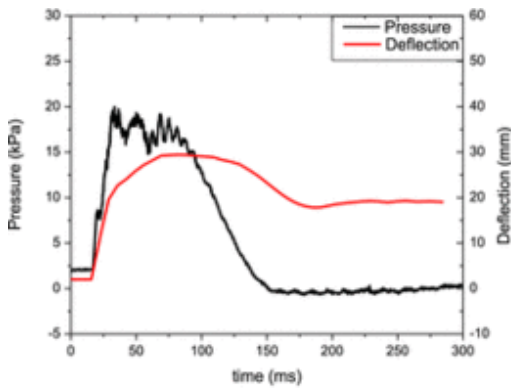

a) $6.38 \mathrm{~mm}$

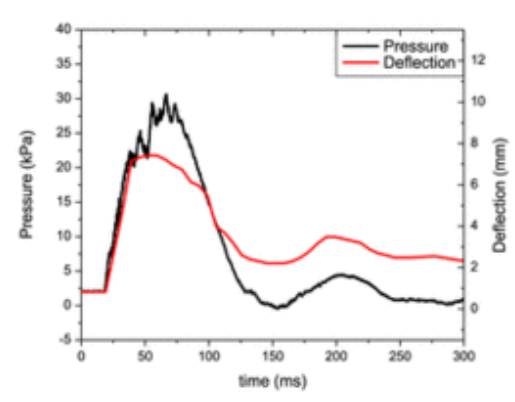

c) $12.38 \mathrm{~mm}$

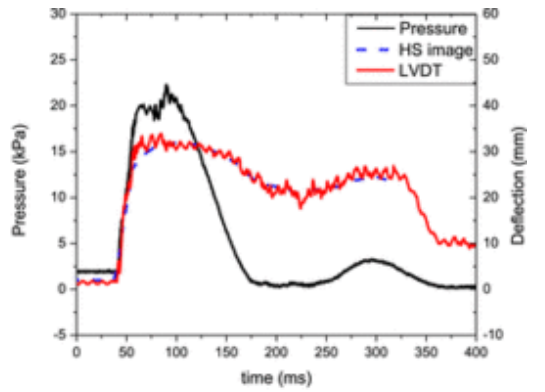

b) $6.76 \mathrm{~mm}$

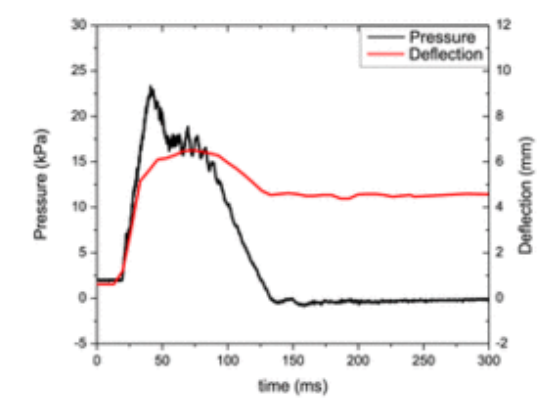

d) $12.76 \mathrm{~mm}$

Fig. 7 Pressure and deflection time histories.

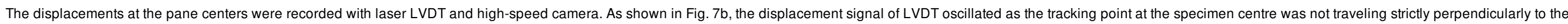

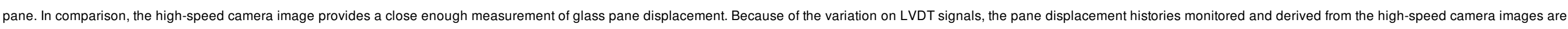

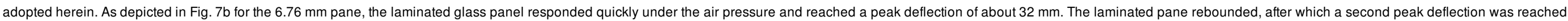

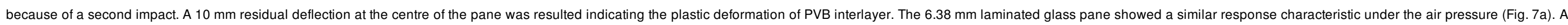

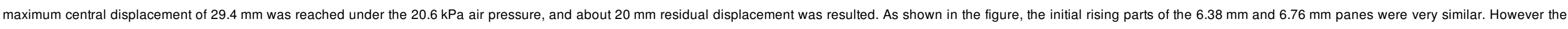

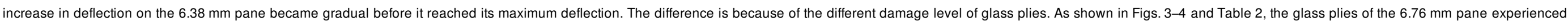

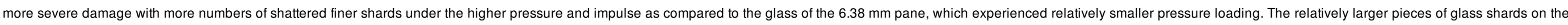

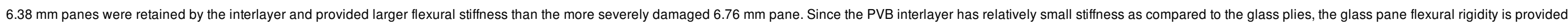

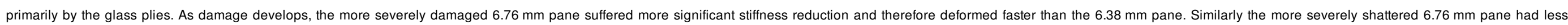

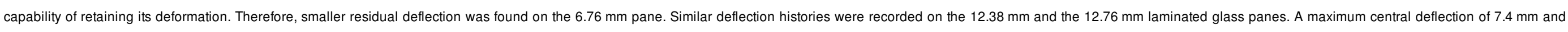

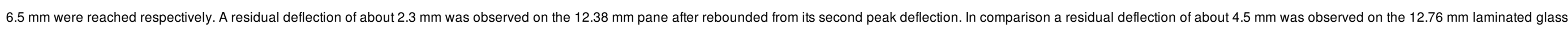

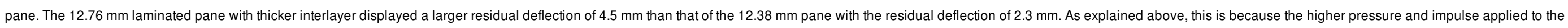
$12.38 \mathrm{~mm}$ pane caused severer damage to glass plies, which lead to more significant stiffness reduction of the glass pane.

Table 2 Summary of pane maximum deflections in laboratory tests.

$$
\text { Test no. Pane thickness }(\mathrm{mm})
$$$$
\text { Maximum deflection (mm) }
$$ 


\begin{tabular}{|c|c|c|c|c|c|c|}
\hline 1 & 6.38 & 29.44 & 10.16 & 29.09 & 28.65 & 28.63 \\
\hline 2 & 6.76 & 31.95 & 11.94 & 30.92 & 30.05 & 30.03 \\
\hline 3 & 12.38 & 7.43 & 3.60 & 6.63 & 6.58 & 6.52 \\
\hline 4 & 12.76 & 6.51 & 3.34 & 5.97 & 5.95 & 5.88 \\
\hline
\end{tabular}

\subsection{Analysis and discussion}

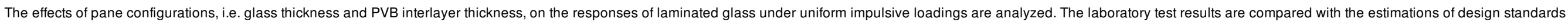
including ASTM F2248, UFC 3-340-02, and those from analysis of the equivalent SDOF systems by Biggs [26] and Morison [5]. The accuracies of the above models are evaluated through comparisons with the testing results.

\subsubsection{Effect of glass thickness}

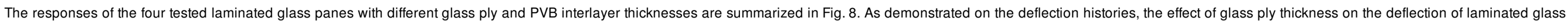

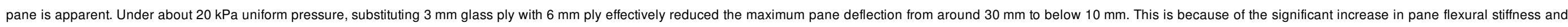

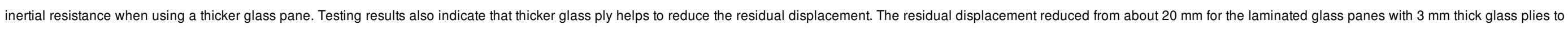
below $5 \mathrm{~mm}$ for those with $6 \mathrm{~mm}$ glass plies.

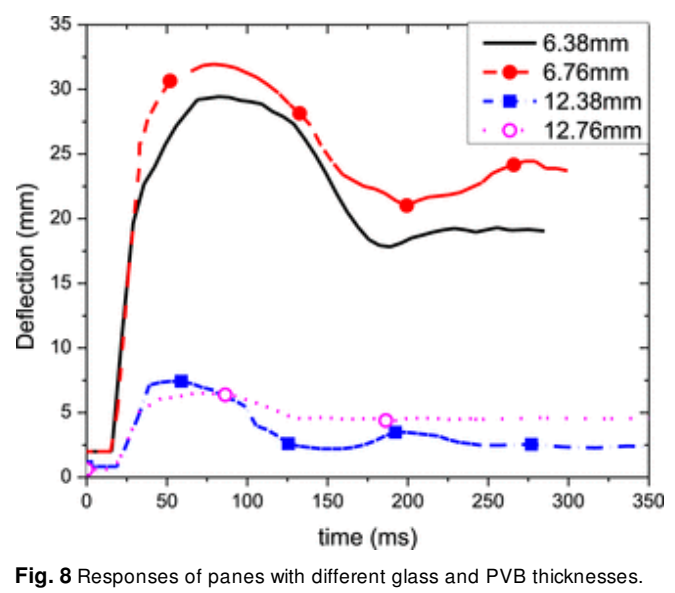

\subsubsection{Effect of interlayer thickness}

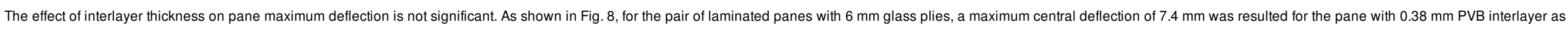

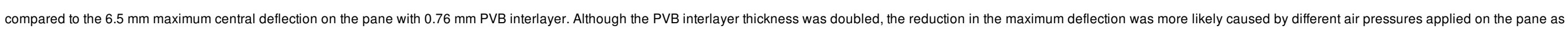

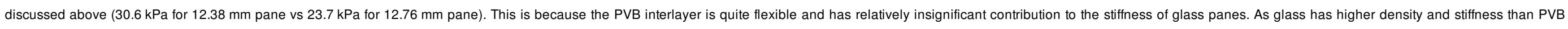

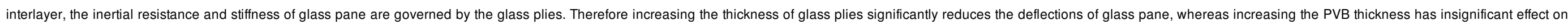

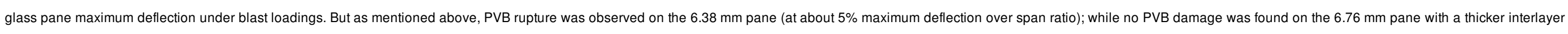

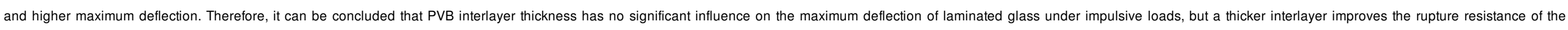
laminated pane.

\subsubsection{Comparison with design standards and SDOF models}

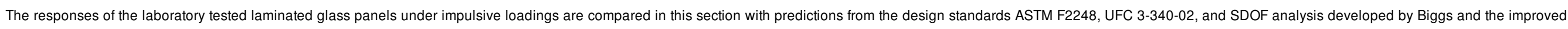




\section{elsevier_IE_2448}

SDOF system for laminated glass by Morison.

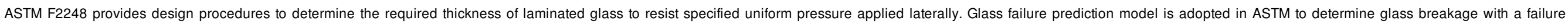

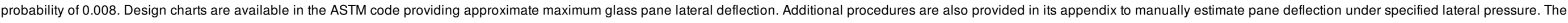

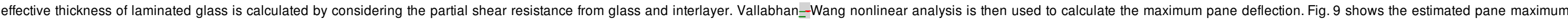

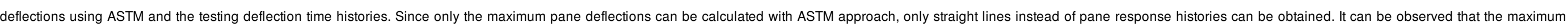

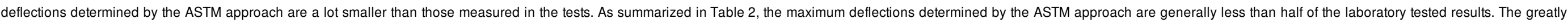
underestimated pane deflections indicate that the ASTM standard overestimates the stiffness of laminated glass and gives very poor estimations on laminated glass deflection when analyzing pane response under impulsive pressure.

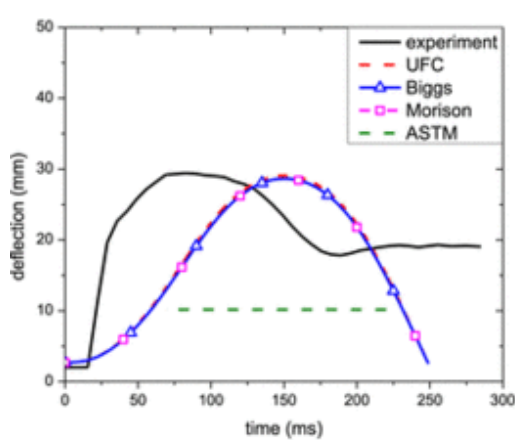

a) $6.38 \mathrm{~mm}$

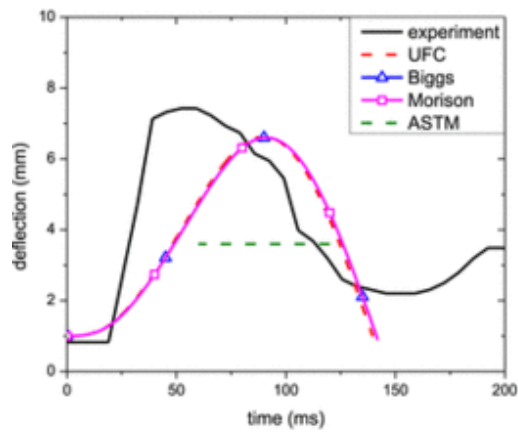

c) $12.38 \mathrm{~mm}$

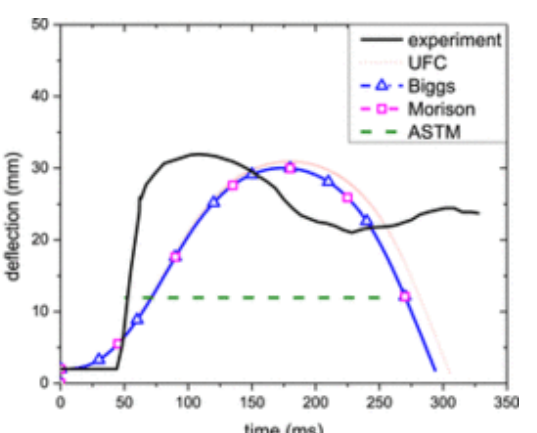

b) $6.76 \mathrm{~mm}$

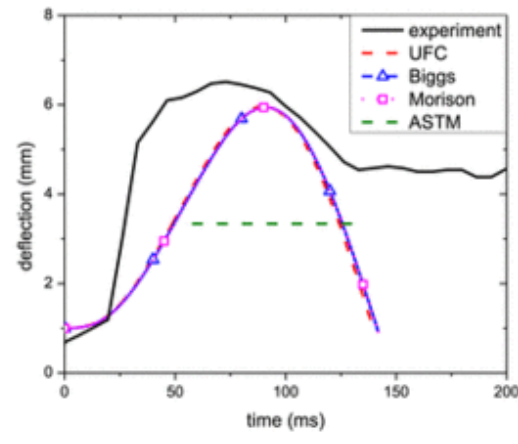

d) $12.76 \mathrm{~mm}$

Fig. 9 Comparisons of glass responses,

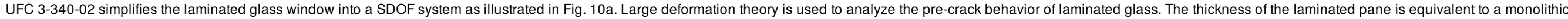

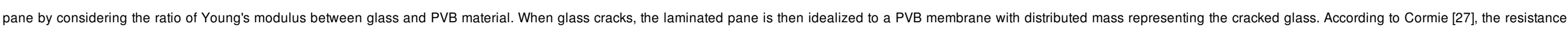

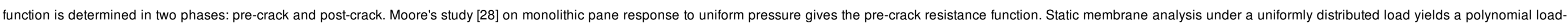

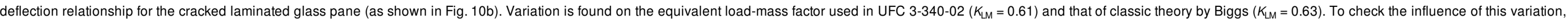

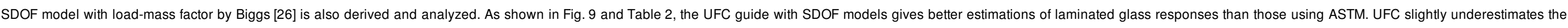

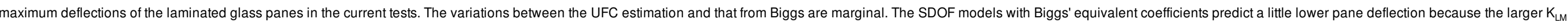

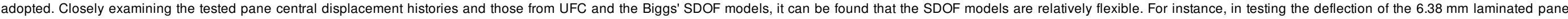

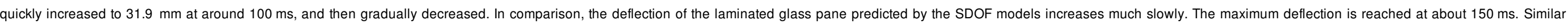

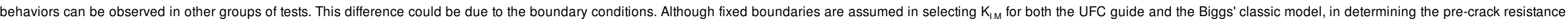




\section{elsevier_IE_2448}

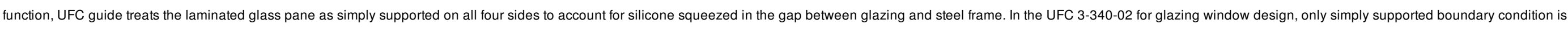

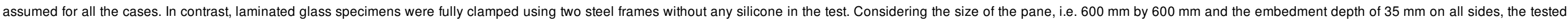

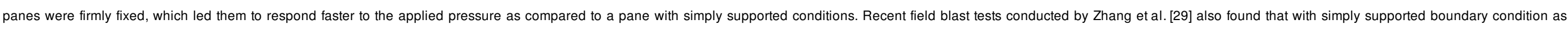

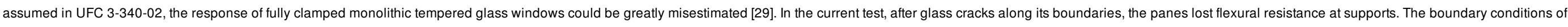

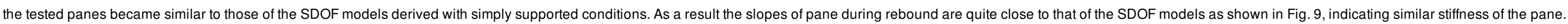

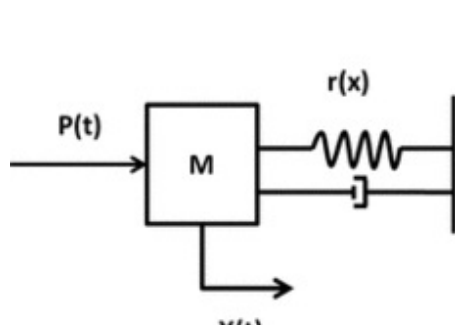

$x(t)$

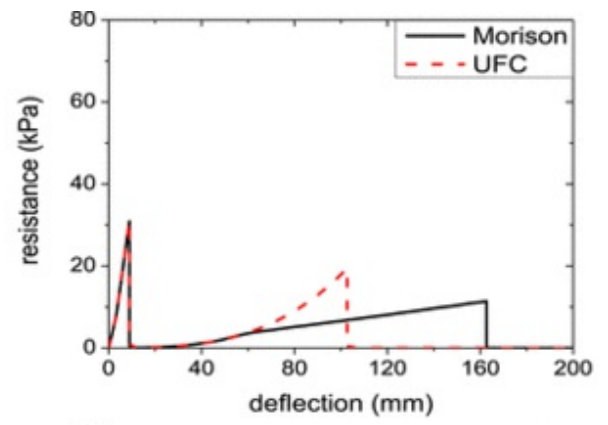

$\begin{array}{ll}\text { a) SDOF model } & \text { b) resistance function of } 6.76 \mathrm{~mm} \text { laminated pane }\end{array}$ Fig. 10 SDOF model and $6.76 \mathrm{~mm}$ laminated glass pane resistance function.

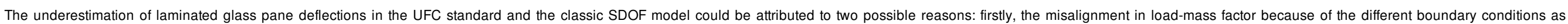

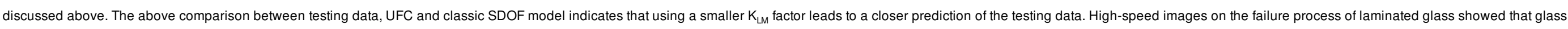

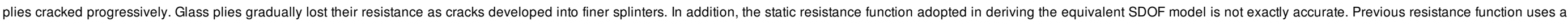

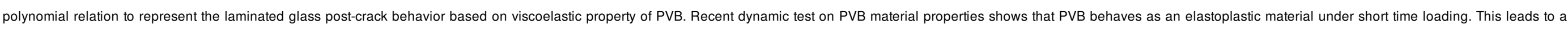

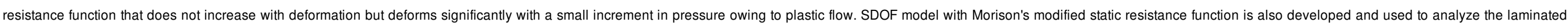

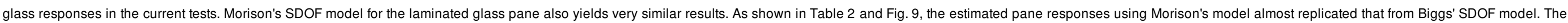

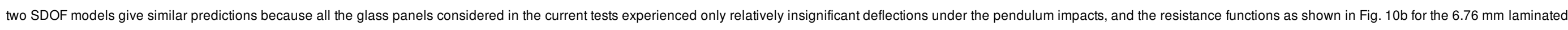
glass for the two models are almost the same when the deflection is smaller than $50 \mathrm{~mm}$.

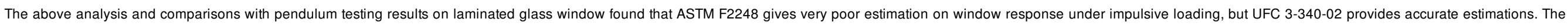

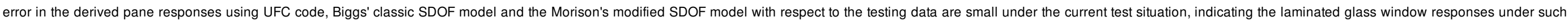

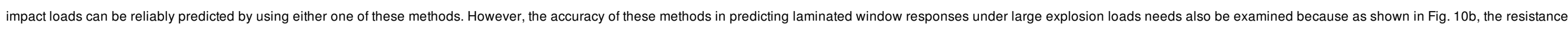
functions in UFC and Morison's model deviate from each other when the deflection is large, which would lead to different response predictions.

\section{Full-scale field blast test}

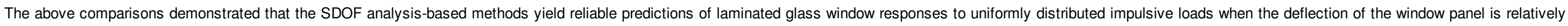
small. Glass windows might be subjected to blast loads with large deflections. The reliability of these methods in predicting the window responses to blast loads is also evaluated in this study.

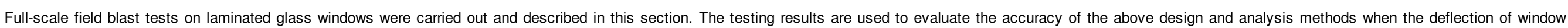

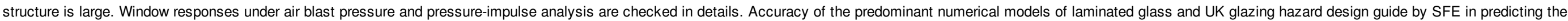
window responses are also included in the evaluation.

\subsection{Test setup and results}

\subsubsection{Testing field}




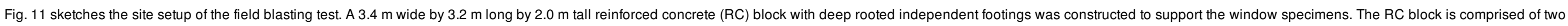

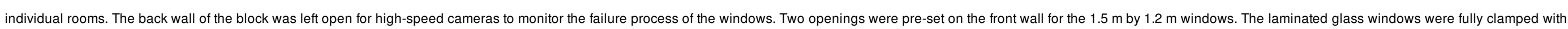

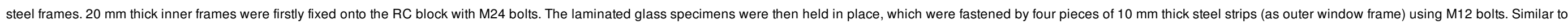
the practice as shown in Fig. 1b, plastic strips were placed in the gap between the inner and outer window frame to avoid damaging glass specimens when fasten the bolts.

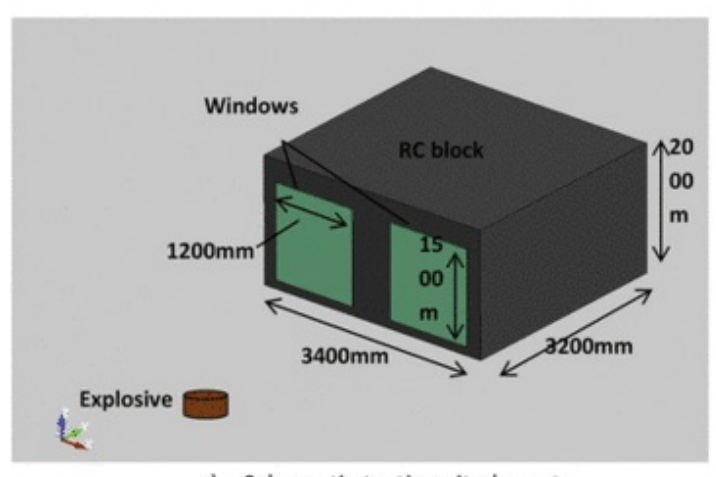

a) Schematic testing site layout

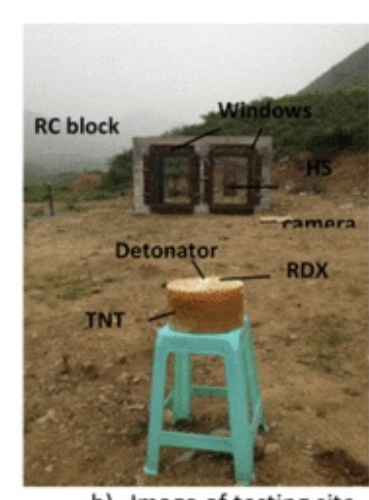

b) Image of testing site

Fig. 11 Sketch of testing setup.

\subsubsection{Testing scenario and data acquisition system}

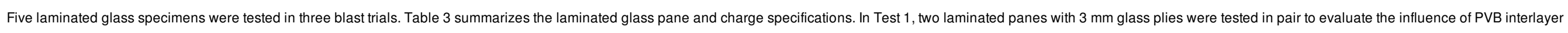

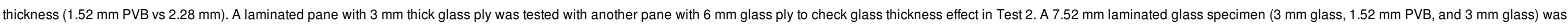

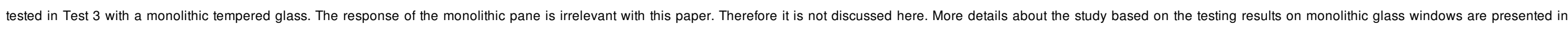
Refs. $[29,30] .10 \mathrm{~kg}$ TNT explosives were positioned at various stand-off distances as listed in Table 3, and detonated in front of the window specimens.

\section{Table 3 Summary of window specimens in field blasting tests.}

\begin{tabular}{|c|c|c|c|c|c|c|c|}
\hline \multirow[t]{2}{*}{ Test no. } & \multirow[t]{2}{*}{ Pane no. } & \multirow{2}{*}{$\begin{array}{l}\text { Glass thickness } \\
\qquad(\mathrm{mm})\end{array}$} & \multirow{2}{*}{$\begin{array}{c}\text { PVB thickness } \\
(\mathrm{mm})\end{array}$} & \multirow{2}{*}{$\begin{array}{c}\text { Size } \\
(\mathrm{mm} \times \mathrm{mm})\end{array}$} & \multirow[t]{2}{*}{ Boundary condition } & \multirow{2}{*}{$\begin{array}{c}W \\
(\mathrm{~kg})\end{array}$} & \multirow{2}{*}{$\begin{array}{l}R \\
(\mathrm{~m})\end{array}$} \\
\hline & & & & & & & \\
\hline 1 & $1-1-1$ & 3 & 1.52 & $1500 \times 1200$ & Fixed & 10 & 10 \\
\hline 1 & $1-1-2$ & 3 & 2.28 & $1500 \times 1200$ & Fixed & 10 & 10 \\
\hline 2 & $2-1-1$ & 3 & 1.52 & $1500 \times 1200$ & Fixed & 10 & 9 \\
\hline 2 & $2-1-2$ & 6 & 1.52 & $1500 \times 1200$ & Fixed & 10 & 9 \\
\hline 3 & $3-1-1$ & 3 & 1.52 & $1500 \times 1200$ & Fixed & 10 & 12.3 \\
\hline
\end{tabular}

Aote: $W$ stands for the weight of TNT explosive, and $R$ stands for the explosive stand-off distance.

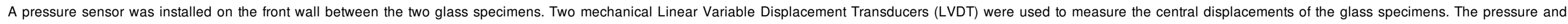

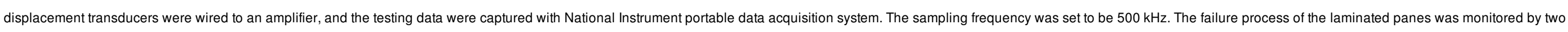

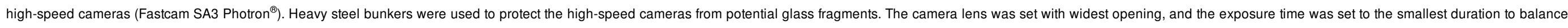

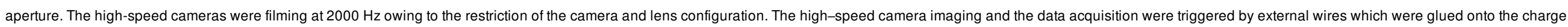




\section{elsevier_IE_2448}

\subsubsection{Pressure time history}

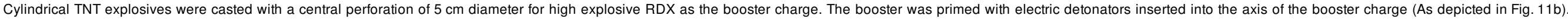

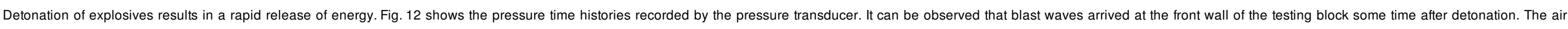

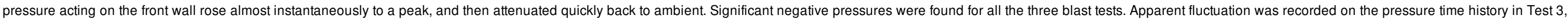
which was likely to be resulted from the fracture of the monolithic glass pane next to the pressure sensor.
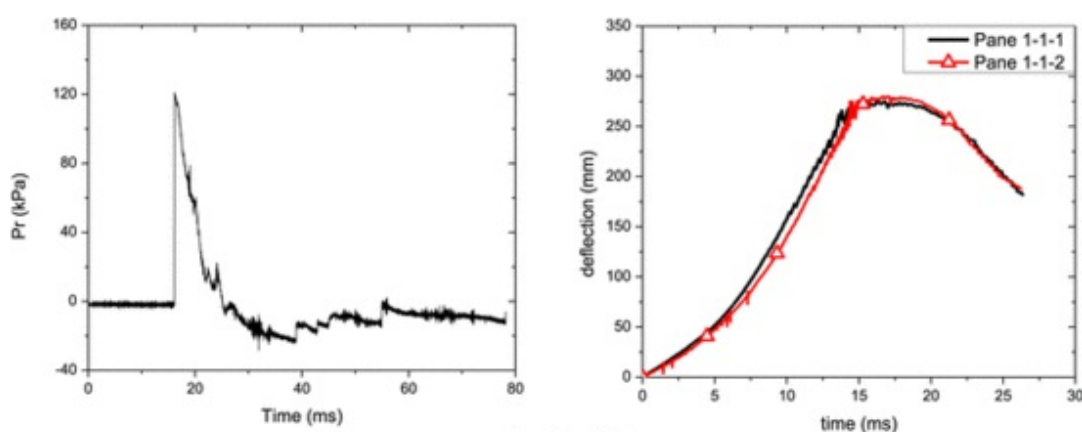

a) Test 1
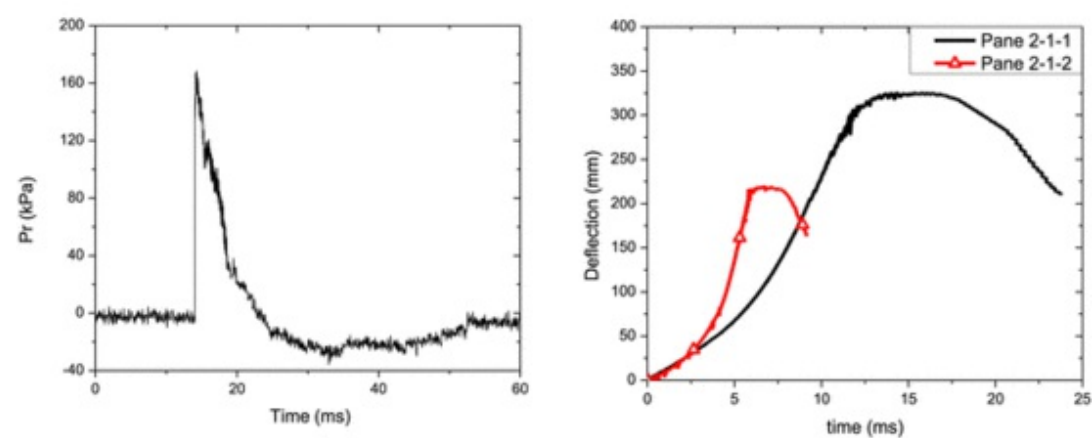

b) Test 2
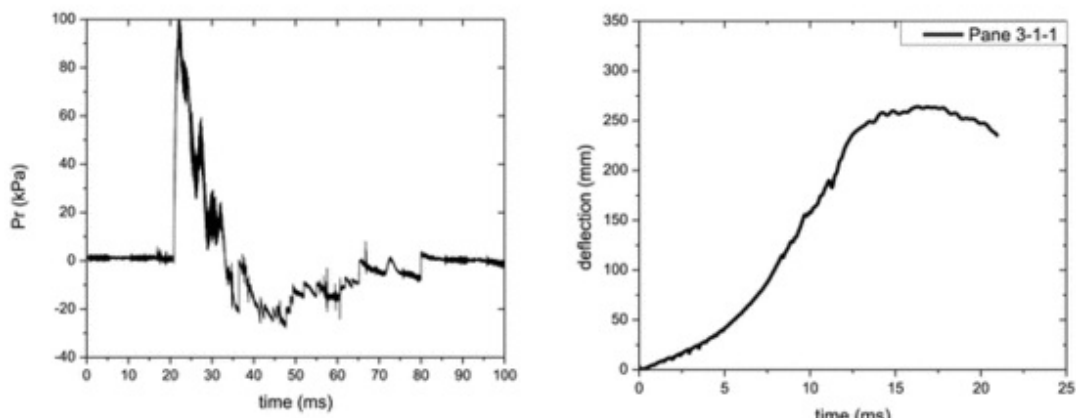

c) Test 3

Fig. 12 Recorded reflected pressures and pane deflection histories. 


\section{elsevier_IE_2448}

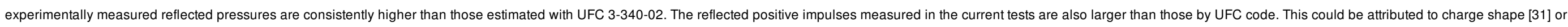
the core booster charge. More variations were found on the negative impulses, which were probably due to the testing site condition, the size and shape of the RC block.

Table 4 Summary of recorded blast loads and UFC estimations.

\begin{tabular}{|c|c|c|c|c|c|c|c|c|}
\hline & & \multirow[b]{3}{*}{$R(m)$} & \multicolumn{6}{|c|}{ Positive phase } \\
\hline & \multirow[b]{2}{*}{ W (kg) } & & \multicolumn{3}{|c|}{$\operatorname{Pr}(\mathrm{kPa})$} & \multicolumn{3}{|c|}{$\operatorname{Ir}(\mathrm{kPa}-\mathrm{ms})$} \\
\hline Test no. & & & Field test & UFC & Var. & Field test & UFC & Var. \\
\hline 1 & 10 & 10 & 121.1 & 117.2 & $3 \%$ & 395.0 & 293.9 & $34 \%$ \\
\hline 2 & 10 & 9 & 168.6 & 147.1 & $15 \%$ & 476.1 & 330.7 & $44 \%$ \\
\hline \multirow[t]{3}{*}{3} & 10 & 12.3 & 82.2 & 78.1 & $5 \%$ & 413.3 & 339.3 & $22 \%$ \\
\hline & & & \multicolumn{6}{|c|}{ Negative phase } \\
\hline & & & \multicolumn{3}{|c|}{$\operatorname{Pr}(\mathrm{kPa})$} & \multicolumn{3}{|c|}{$\operatorname{Ir}(\mathrm{kPa}-\mathrm{ms})$} \\
\hline Test no. & W (kg) & $\mathrm{R}(\mathrm{m})$ & Field test & UFC & Var. & Field test & UFC & Var. \\
\hline 1 & 10 & 10 & -28.4 & -16.3 & $74 \%$ & 319.7 & 92.5 & $246 \%$ \\
\hline 2 & 10 & 9 & -35.8 & -18.3 & $96 \%$ & 543.5 & 101.4 & $436 \%$ \\
\hline 3 & 10 & 12.3 & -17.5 & -13.1 & $34 \%$ & 261.7 & 212.8 & $23 \%$ \\
\hline
\end{tabular}

\subsubsection{Deformation process and failure pattern}

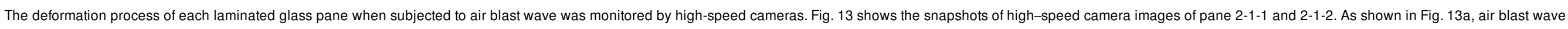

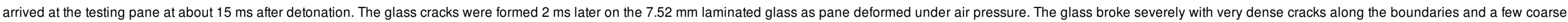
cracks at pane centre. Significant deformation pulled the cracked laminated pane out of the frame along two vertical boundaries. At about $50 \mathrm{~ms}$, the pane was totally dragged out of the frame during rebound. 



\section{elsevier_IE_2448}

within the window frame.

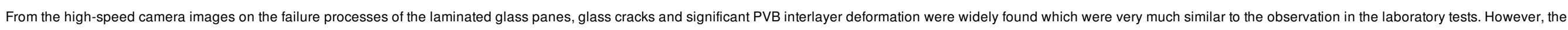

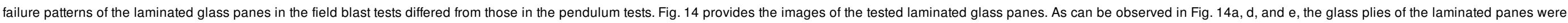

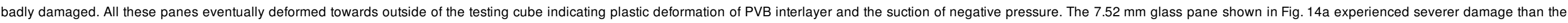

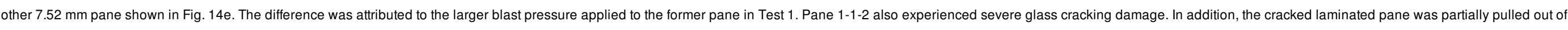

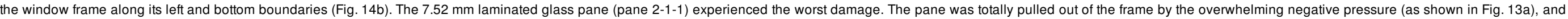

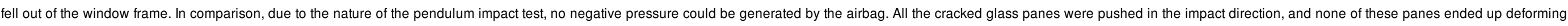

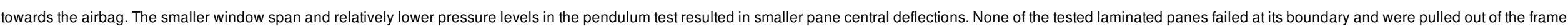
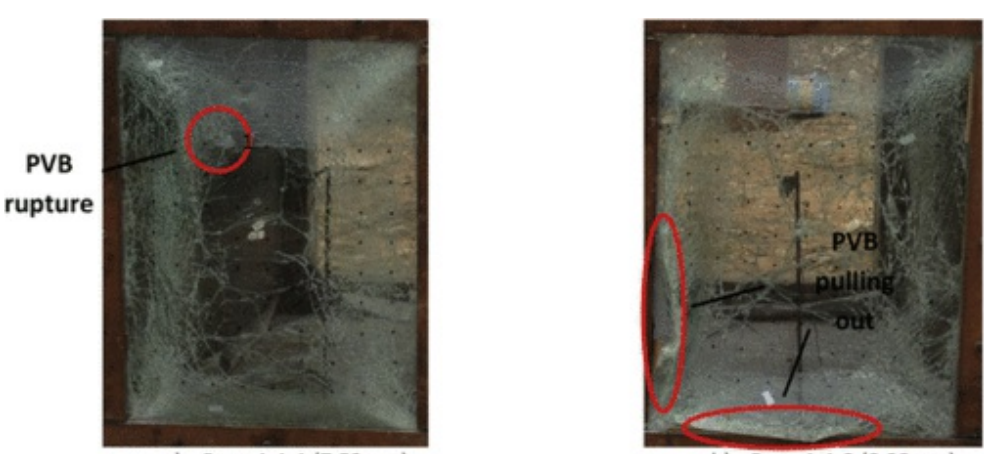

a) Pane 1-1-1 $(7.52 \mathrm{~mm})$

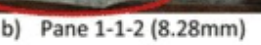

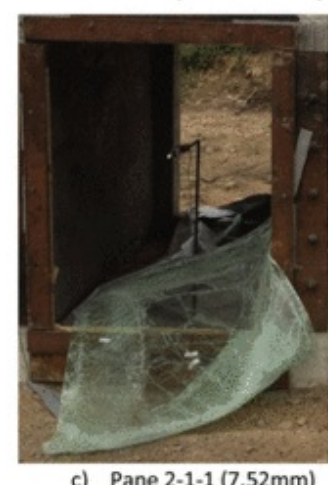

c) Pane 2-1-1 $(7.52 \mathrm{~mm})$

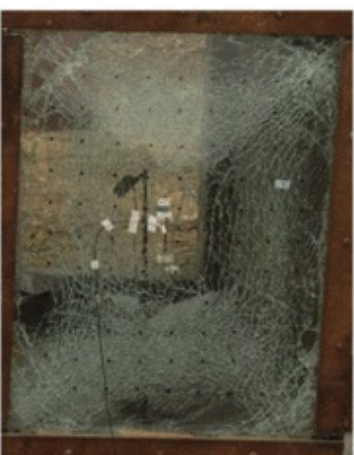

d) Pane 2-1-2 (13.52mm)

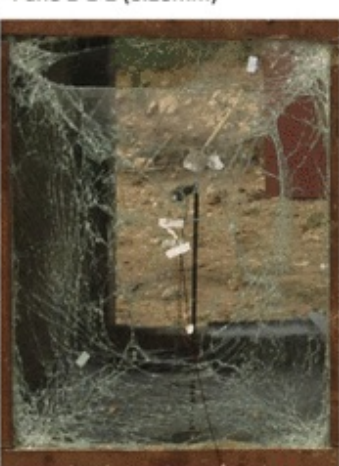

e) Pane 3-1-1 $(7.52 \mathrm{~mm})$

\subsubsection{Displacement history}

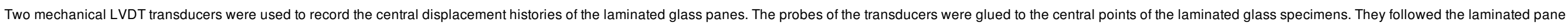

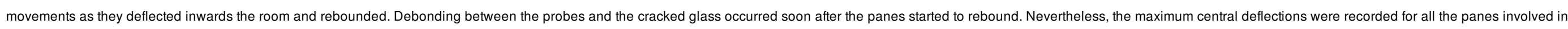
the current tests.

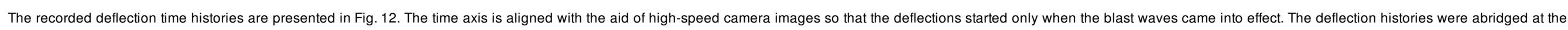

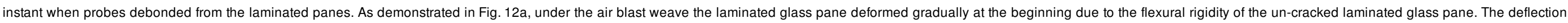

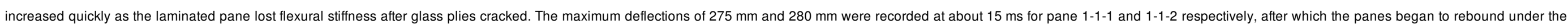

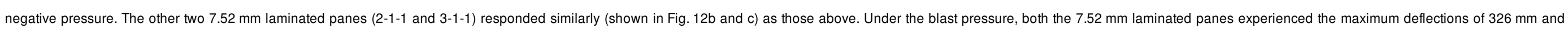




\section{elsevier_IE_2448}

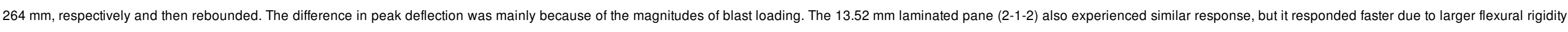
with a smaller maximum central deflection of $220 \mathrm{~mm}$. The maximum central deflections together with the associated positive reflected pressures and impulses are summarized in Table 5 .

Table 5 Summary of window responses in field blasting tests.

\begin{tabular}{|c|c|c|c|c|c|c|}
\hline \multirow[t]{2}{*}{ Test no. } & \multirow[t]{2}{*}{ Pane no. } & \multirow{2}{*}{$\begin{array}{c}\text { Glass thickness } \\
(\mathrm{mm})\end{array}$} & \multirow{2}{*}{$\begin{array}{c}\text { PVB thickness } \\
(\mathrm{mm})\end{array}$} & \multirow{2}{*}{$\begin{array}{c}\mathrm{Pr} \\
(\mathrm{kPa})\end{array}$} & \multirow{2}{*}{$\begin{array}{c}\text { Ir } \\
(\mathrm{kPa}-\mathrm{ms})\end{array}$} & \multirow{2}{*}{$\begin{array}{l}w_{\max } \\
(\mathrm{mm})\end{array}$} \\
\hline & & & & & & \\
\hline 1 & $1-1-1$ & 3 & 1.52 & 121 & 395 & 275 \\
\hline 1 & $1-1-2$ & 3 & 2.28 & 121 & 395 & 280 \\
\hline 2 & $2-1-1$ & 3 & 1.52 & 169 & 476 & 326 \\
\hline 2 & $2-1-2$ & 6 & 1.52 & 169 & 476 & 220 \\
\hline 3 & $3-1-1$ & 3 & 1.52 & 82 & 413 & 264 \\
\hline
\end{tabular}

\subsection{Analysis and discussion}

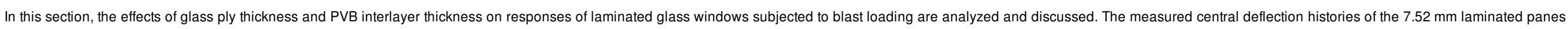

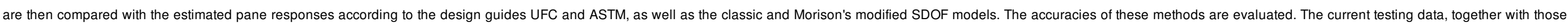
obtained by other researchers are also used to check the accuracy of the $P_{-}$Idiagrams generated by the above methods and by some recent numerical models.

\subsubsection{Glass thickness influence}

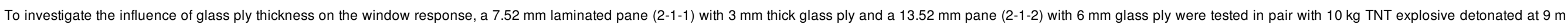

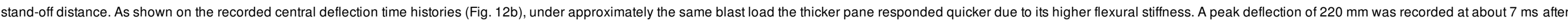

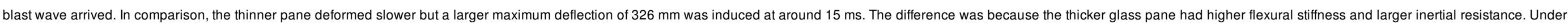

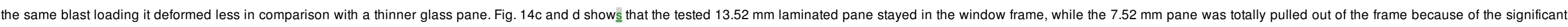

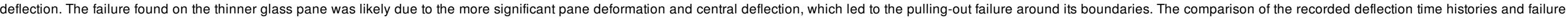
images indicates that thicker glass panes have higher blast loading-resistant capacities.

\subsubsection{Interlayer thickness}

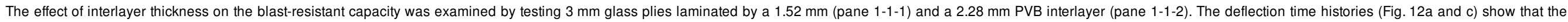

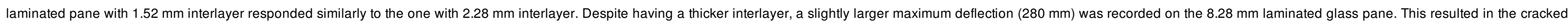
laminated pane being partial pulled-out of the window boundary as shown in Fig. 14b.

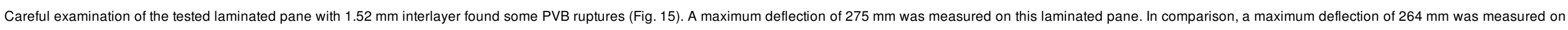

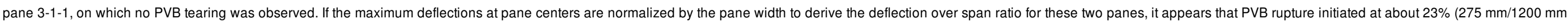

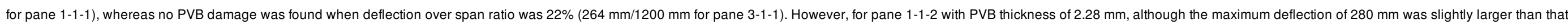

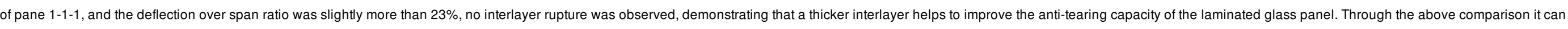
be found that a thicker PVB interlayer does not result in lower pane deflection as its enhancement on pane stiffness and inertial resistance is insignificant, but it reduces the PVB rupture potential. 


\section{elsevier_IE_2448}

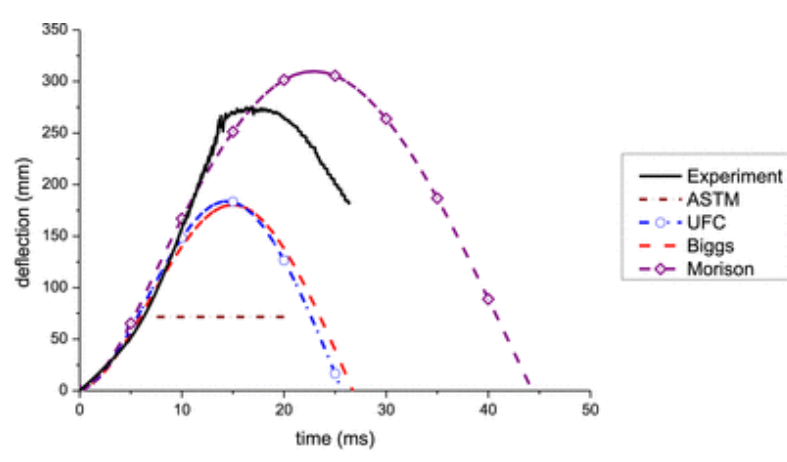

a) Pane 1-1-1

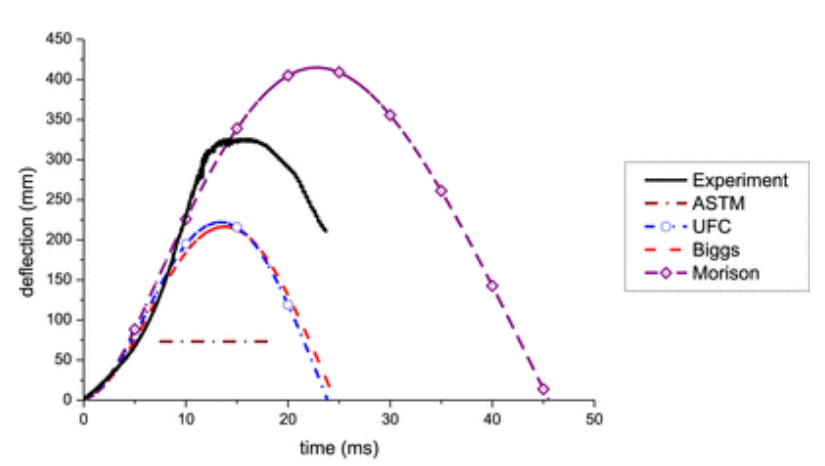

b) Pane 2-1-1

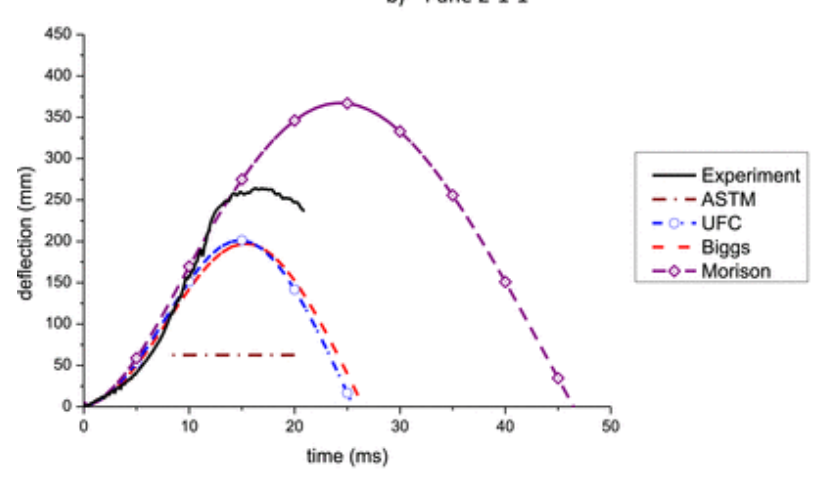

c) Pane 3-1-1

Fig. 16 Comparisons of panel responses recorded in the current tests and predicted by various methods.

\subsubsection{Comparison with design guides and SDOF methods}

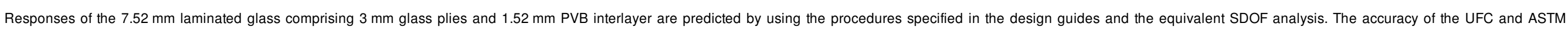

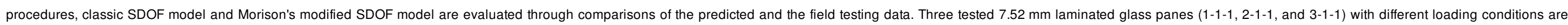
considered.

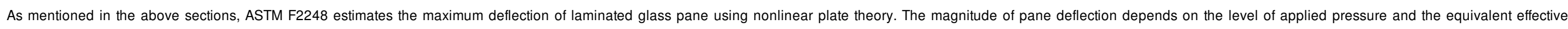




\section{elsevier_IE_2448}

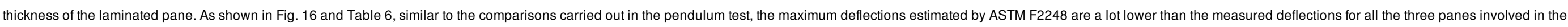

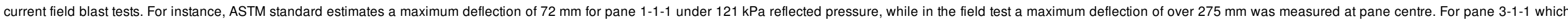

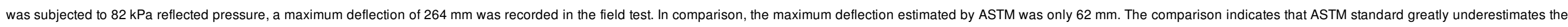
responses of laminated glass under blast loadings.

Table 6 Summary of maximum deflections.

\begin{tabular}{|c|c|c|c|c|c|}
\hline \multirow[t]{2}{*}{ Pane no. } & \multicolumn{5}{|c|}{$w_{\max }(\mathrm{mm})$} \\
\hline & Experiment & ASTM & UFC3 & Biggs & Morison \\
\hline $1-1-1$ & 275 & 72 & 181 & 184 & 310 \\
\hline $2-1-1$ & 326 & 73 & 222 & 229 & 415 \\
\hline $3-1-1$ & 264 & 62 & 201 & 204 & 367 \\
\hline
\end{tabular}

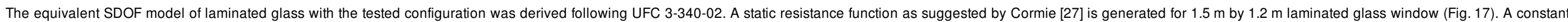

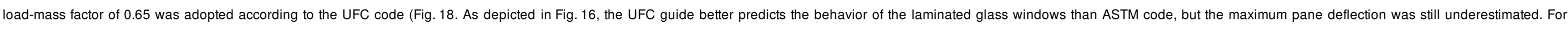

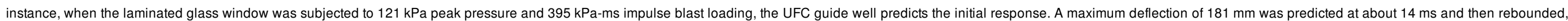

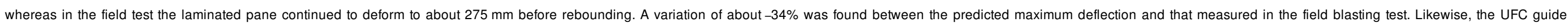
underestimates the maximum deflections of the laminated pane by $32 \%$ and $24 \%$, respectively for pane 2-1-1 and $3-1-1$.

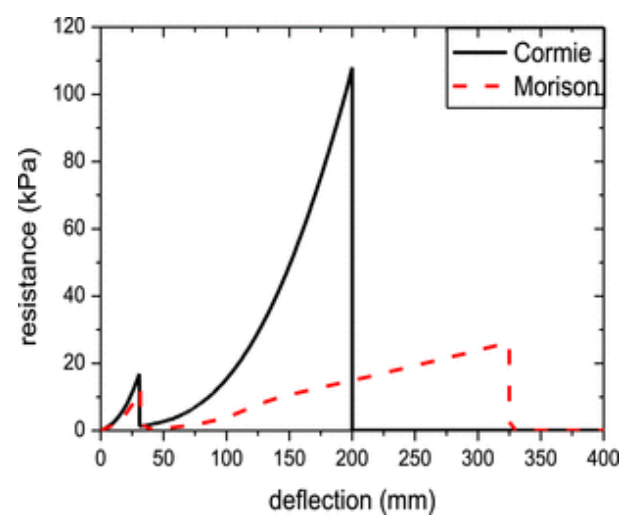

Fig. $177.52 \mathrm{~mm}$ laminated glass pane resistance function. 


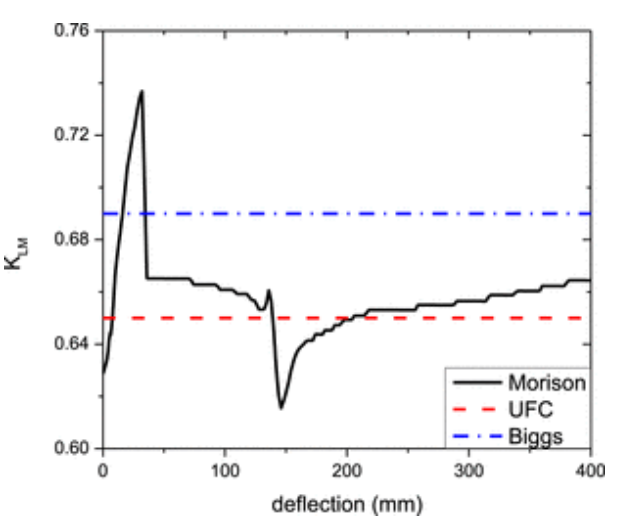

Fig. 18 The load-mass factors $K_{L M}$ in different SDOF models (with span ratio 1.25).

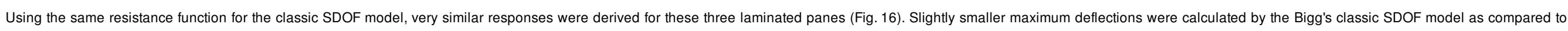

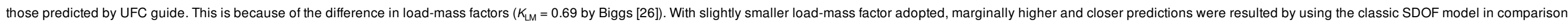

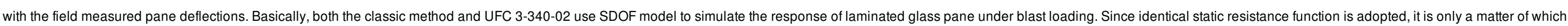

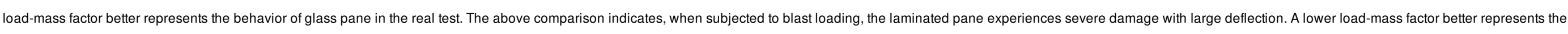
situation of the cracked laminated pane. Therefore, the classic SDOF model with a smaller load-mass factor gives a slightly closer prediction.

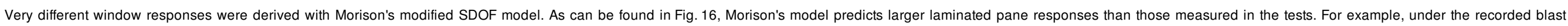

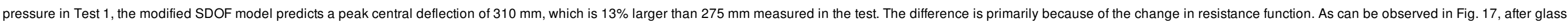

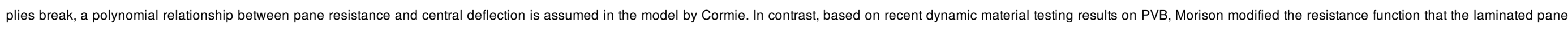

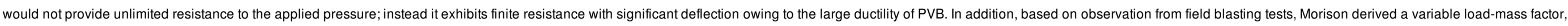

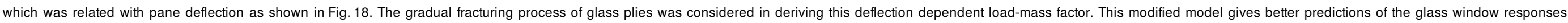

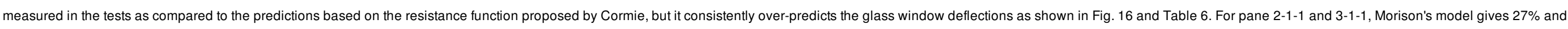

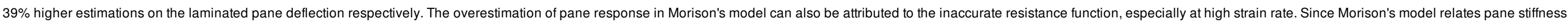

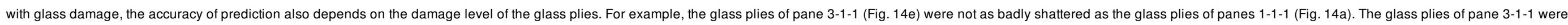

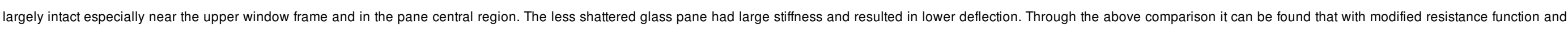
load-mass factor, Morison's model gives more conservative prediction with higher pane deflection. The accuracy of prediction using Morison's model heavily depends on the glass damage and fracture level.

\subsubsection{Pressure impulse analysis}

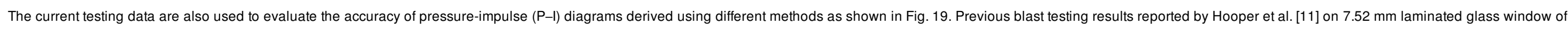

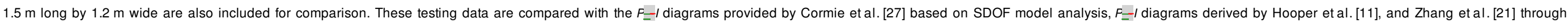

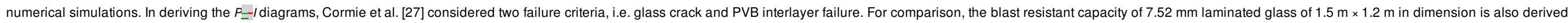

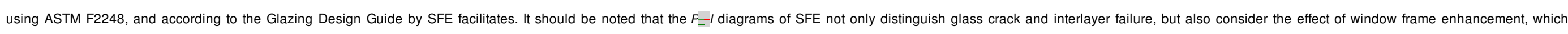
supposedly give better and more comprehensive predictions of the blast resistant capacities of the laminated glass window. 


\section{elsevier_IE_2448}
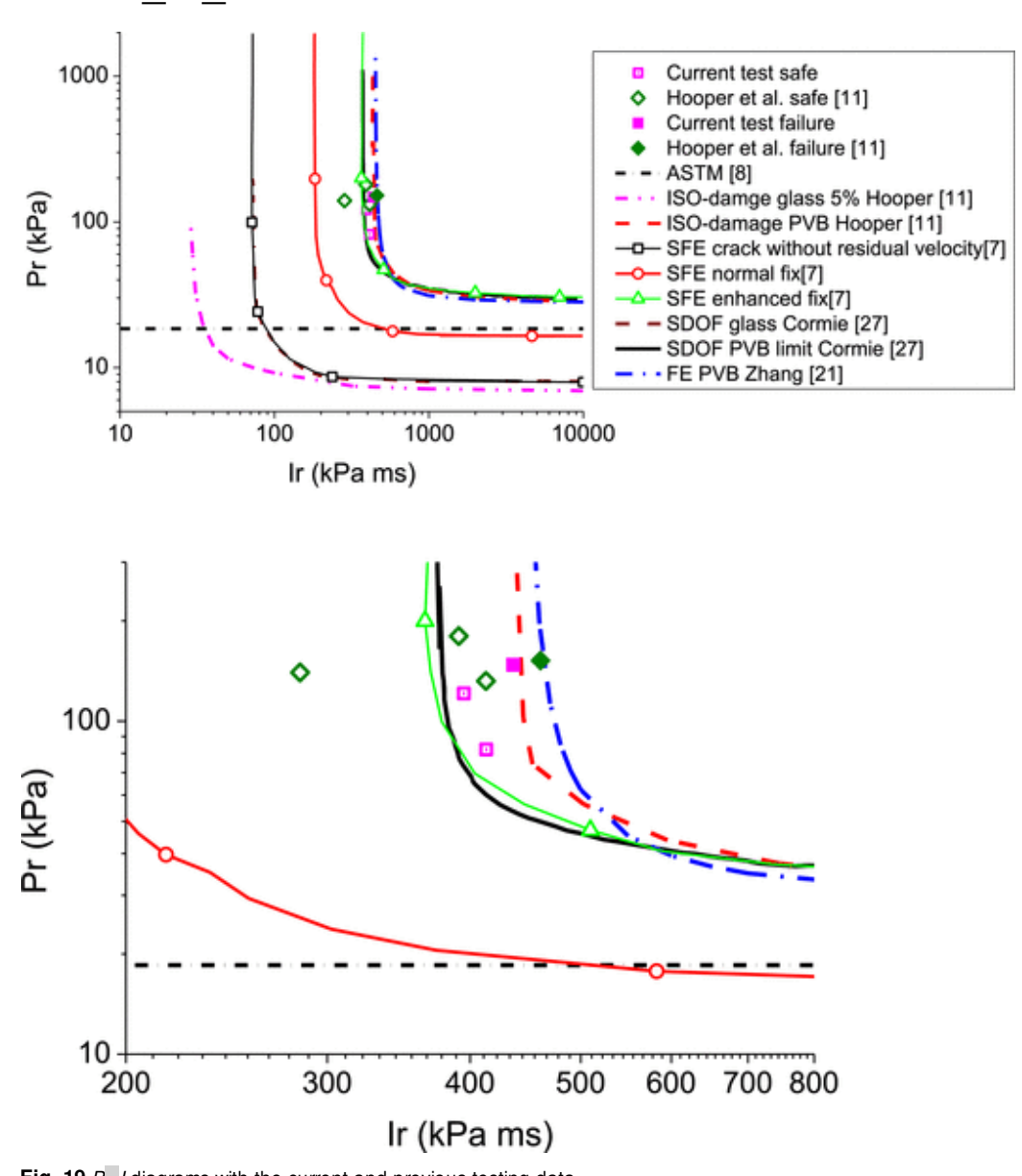

Fig. $19 P_{-}=$/diagrams with the current and previous testing data.

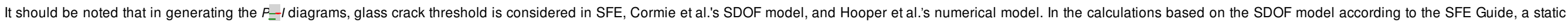

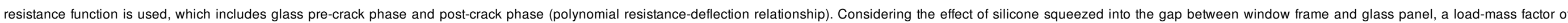

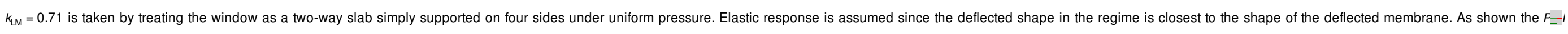

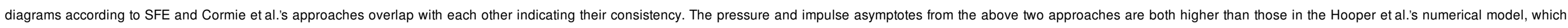

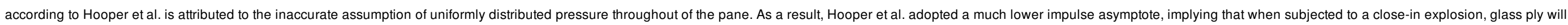

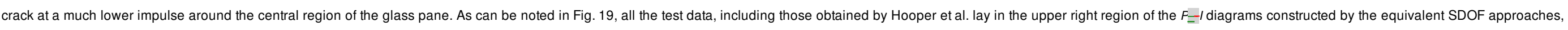

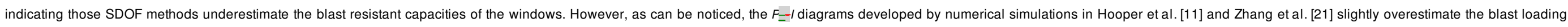

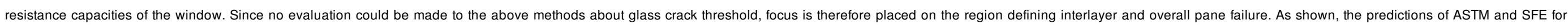

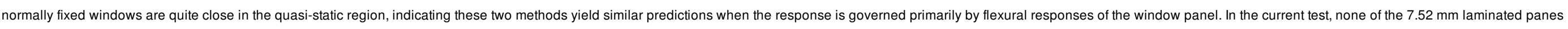

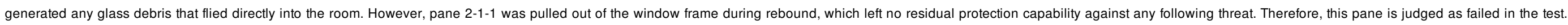

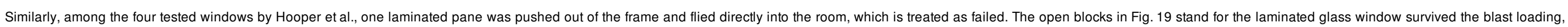

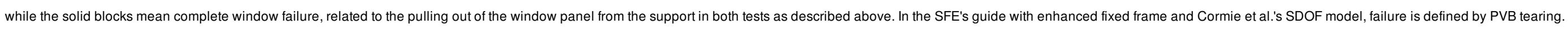




\section{elsevier_IE_2448}

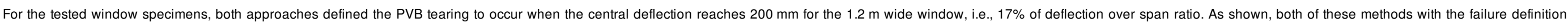

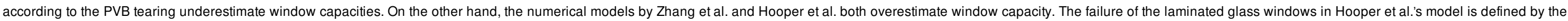

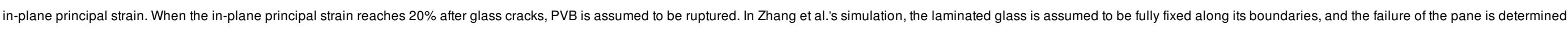

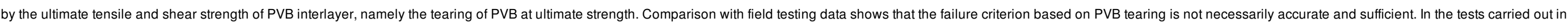

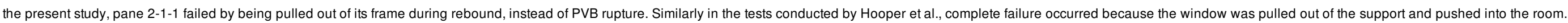
The possible pull-out failure of the glass pane from its support is not considered in the two numerical models, therefore they over predict the glass window capacities.

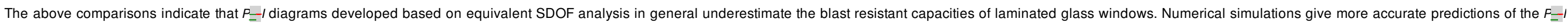
diagrams, however, the possible pulling out failure of the window panel from its support should also be considered in the simulations.

\section{Conclusion}

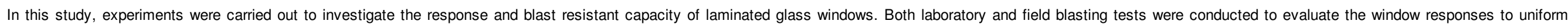

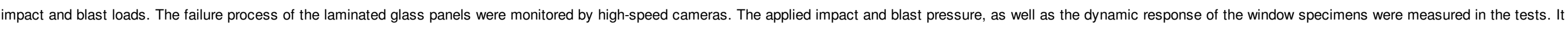

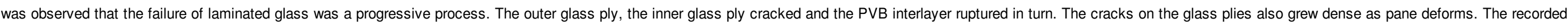

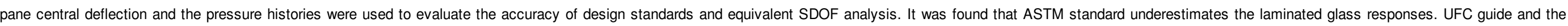

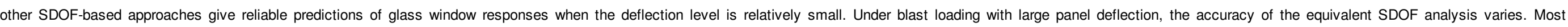

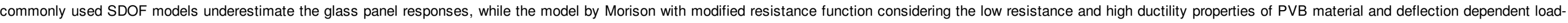

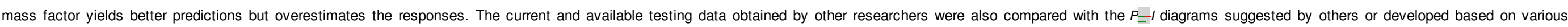

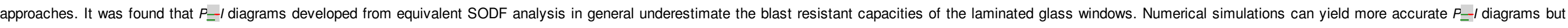
pulling out failure of the glass pane from its support should be considered in the simulations.

\section{AcknowledgementAcknowledgment}

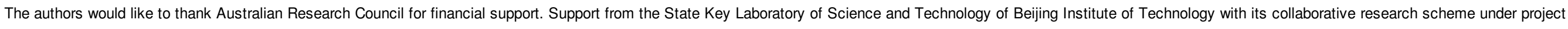
number KFJJ11-3 is also acknowledged. The first author would also like to thank the University of Western Australia for providing Ad Hoc scholarship.

\section{References}

[1]

L.H. Lin, E. Hinman, H.F. Stone and A.M. Roberts, Survey of window retrofit solutions for blast mitigation, J Perform Constr Facil 18, $2004,86-94$.

[2]

M. Larcher, G. Solomos, F. Casadei and N. Gebbeken, Experimental and numerical investigations of laminated glass subjected to blast loading, Int J Impact Eng 39, 2012 , 42-50.

[3]

J. Wei, M.S. Shetty and L.R. Dharani, Stress characteristics of a laminated architectural glazing subjected to blast loading, Comput Struct 84, 2006, 699-707.

[4]

A.V. Duser, A. Jagota and S.J. Bennison, Analysis of glass/polyvinyl butyral laminates subjected to uniform pressure, J Eng Mech 125, $1999,435-442$.

[5]

C. Morison, The resistance of laminated glass to blast pressure loading and the coefficients for single degree of freedom analysis of laminated glass, [PhD thesis]2010, Cranfield University.

[6]

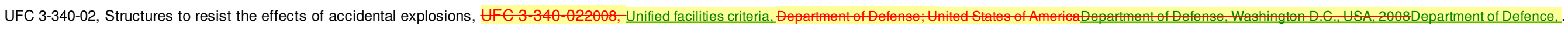




\section{elsevier_IE_2448}

\section{[7]}

Security Facilities Executive Special Services Group, Explosion protection. gy Glazing hazard guide, 1997, Gabinet Offiee; London Cabinet Office, London, 1997.

[8] ASTM F2248-09, Standard practice for specifying an equivalent 3-second duration design loading for blast resistant glazing fabricated with laminated glass, West Conshohocken, PA_2009.

[9]

Washington D.C., USA, UFC 4-010-01Unified facilities criteria DoD minimum antiterrorism standards for buildings, 2003.

[10]

J. Wei and L.R. Dharani, Response of laminated architectural glazing subjected to blast loading, Int J Impact Eng 32, 2006, $2032-2047$.

[11]

P.A. Hooper, R.A.M. Sukhram, B.R.K. Blackman and J.P. Dear, On the blast resistance of laminated glass, Int J Solids Struct 49, 2012, 899-918.

[12]

S. Bennison, J. Sloan, D. Kistunas, P. Buehler, T. Amos and C. Smith, Laminated glass for blast mitigation: role of interlayer properties, In: Glass processing days. Tampere, Finland, 2005.

[13]

R. Iwasaki, C. Sato, J. Latailladeand and P. Viot, Experimental study on the interface fracture toughness of PVB (polyvinyl butyral)/glass at high strain rates, Int J Crashworthiness 12, 2007, 293-298.

[14]

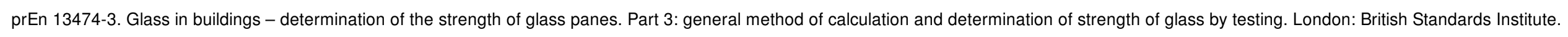

[15]

M. Overend, G. Parke and D. Buhagiar, Predicting failure in glass-a general crack growth model, J Struct Eng 133, 2007, 1146-1155.

[16]

W.L. Beason and J.R. Morgan, Glass failure prediction model, J Struct Eng 110, 1984, 197-212.

[17]

X. Zhang, Y. Zou, H. Hao, X. Li, G. Ma and K. Liu, Laboratory test on dynamic material properties of annealed float glass, Int J Prot Struct 3, 2012, 407-430.

[18]

M. Peroni, G. Solomos, V. Pizzinato and M. Larcher, Experimental investigation of high strain-rate behaviour of glass, App/ Mech Mater 82, $2011,63-68$.

[19]

X. Zhang and H. Hao, Dynamic material model of annealed soda-lime glass, [under review with] Int J Impact Eng 2014.

[20]

X. Zhang, H. Hao and G. Ma, Laboratory test and numerical simulation of laminated glass window vulnerability to debris impact, Int J Impact Eng 55, $2013,49-62$.

[21]

X. Zhang, H. Hao and G. Ma, Parametric study of laminated glass window response to blast loads, Eng Struct 56, 2013, 1707-1717.

[22]

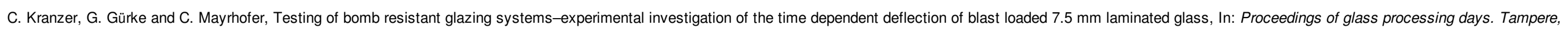




\section{elsevier_IE_2448}

Finland, 2005

[23]

ASTM D3420-08a. Standard test method for pendulum impact resistance of plastic film. West Conshohocken, PA.

\section{[24]}

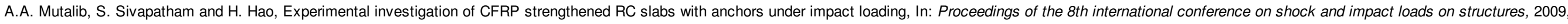
$457-465$.

\section{[25]}

W. Chen and H. Hao, Experimental investigations and numerical simulations of multi-arch double-layered panels under uniform impulsive loadings, Int J Impact Eng 63, 2014, 140-157.

\section{[26]}

J.M. Biggs, Introduction to structural dynamics, New York1964.

[27]

D. Cormie, G. Mays and P. Smith, Blast effects on buildings, 2009, Thomas Telford Publications; Heron Quay, London.

[28]

D.M. Moore, Proposed method for determining the thickness of glass in solar collector panels, NASA ST/Recon Technical Report N 80, 1980, 24755.

[29]

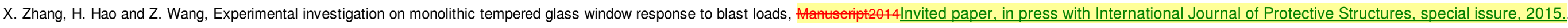

[30]

X. Zhang, H. Hao and Z. Wang, Experimental investigation of monolithic tempered glass fragment characteristics subjected to blast loads, Eng Struct 75, 2014, 259-275.

[31]

C. Wu, D.J. Oehlers, M. Rebentrost, J. Leach and A.S. Whittaker, Blast testing of ultra-high performance fibre and FRP-retrofitted concrete slabs, Eng Struct 31, 2009, 2060-2069.

Highlights

- Laboratory airbag pendulum impact tests were performed on laminated glass panels of various thicknesses.

- Full-scale field blast tests were carried out on laminated glass windows.

- The failure process, applied pressure, and laminated pane deflections were monitored and recorded.

- The responses of the tested windows in the lab and field tests were used to evaluate the accuracy of the predictions of design standards, SDOF models

- The adequacy of available simplified approaches and numerical methods in predicting laminated glass window responses were discussed.

\section{Queries and Answers}

Query: Please provide the grant number for 'Australian Research Council' if any.

Answer: Do not need to specify grant number for Australian Research Council fund. 


\section{elsevier_IE_2448}

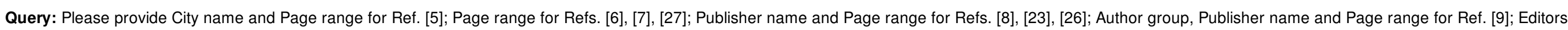
name, Publisher name and Page range for Refs. [12], [22]; Year of Ref. [14]; Publisher name and City name for Ref. [24]; Publisher name, City name and Page range for Ref. [29].

Answer: Please refer to attachment.

Query: Please update Ref. [19].

Answer: X.Zhang, H.Hao, and G.Ma, Dynamic material model of annealed soda-lime glass, International Journal of Impact Engineering 77, 2015, 108-119.

Query: Please check Ref. [30], and correct if necessary.

Answer: No problem.

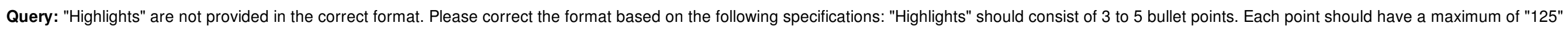
characters including spaces.

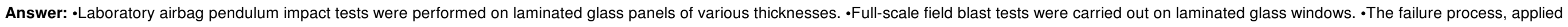

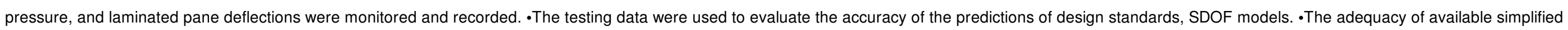
approaches and numerical methods were discussed.

Query: Please confirm that given names and surnames have been identified correctly.

Answer: No problem. 